ARTICLE

DOI: $10.1038 / \mathrm{s} 41467-018-05910-1$

\title{
NF- $\kappa B$ inhibition rescues cardiac function by remodeling calcium genes in a Duchenne muscular dystrophy model
}

Jennifer M. Peterson1,2,3,7, David J. Wang 1,3,8, Vikram Shettigar 2,3,4, Steve R. Roof 2,3,4,9, Benjamin D. Canan 2,3,4, Nadine Bakkar 1,2,3,10, Jonathan Shintaku (1) 1,2,3,11, Jin-Mo Gu1,2,3,12, Sean C. Little 2,3,4,13, Nivedita M. Ratnam ${ }^{1,3}$, Priya Londhe 1,2,3,14, Leina Lu ${ }^{5,15}$, Christopher E. Gaw (10) 3,16, Jennifer M. Petrosino ${ }^{2,3}$, Sandya Liyanarachchi ${ }^{1,3}$, Huating Wang ${ }^{5}$, Paul M.L. Janssen 2,3,4, Jonathan P. Davis, 2,3,4, Mark T. Ziolo, 2,3, Sudarshana M. Sharma (iD ${ }^{6}$ \& Denis C. Guttridge $e^{1,2,3,8}$

Duchenne muscular dystrophy (DMD) is a neuromuscular disorder causing progressive muscle degeneration. Although cardiomyopathy is a leading mortality cause in DMD patients, the mechanisms underlying heart failure are not well understood. Previously, we showed that $\mathrm{NF}-\mathrm{\kappa B}$ exacerbates DMD skeletal muscle pathology by promoting inflammation and impairing new muscle growth. Here, we show that NF-kB is activated in murine dystrophic $(m d x)$ hearts, and that cardiomyocyte ablation of NF- $\mathrm{KB}$ rescues cardiac function. This physiological improvement is associated with a signature of upregulated calcium genes, coinciding with global enrichment of permissive H3K27 acetylation chromatin marks and depletion of the transcriptional repressors CCCTC-binding factor, SIN3 transcription regulator family member $\mathrm{A}$, and histone deacetylase 1. In this respect, in DMD hearts, NF-KB acts differently from its established role as a transcriptional activator, instead promoting global changes in the chromatin landscape to regulate calcium genes and cardiac function.

\footnotetext{
${ }^{1}$ Department of Cancer Biology and Genetics, Columbus, OH 43210, USA. ${ }^{2}$ Center for Muscle Health and Neuromuscular Disorders, Columbus, OH 43210 USA. ${ }^{3}$ The Ohio State University Medical Center, Columbus, OH 43210, USA. ${ }^{4}$ Department of Physiology and Cell Biology, The Ohio State University Medical Center, Columbus 43210 Ohio, USA. ${ }^{5}$ Li Ka Shing Institute of Health Sciences, The Chinese University of Hong Kong, Hong Kong, China.

${ }^{6}$ Department of Biochemistry and Molecular Biology, Medical University of South Carolina, Charleston, SC 29425, USA. ${ }^{7}$ Present address: Department of Pharmacy and Pharmaceutical Sciences, SUNY Binghamton University, Binghamton, NY 13902, USA. ${ }^{8}$ Present address: Department of Pediatrics, Medical University of South Carolina, Charleston, South Carolina 29425, USA. ${ }^{9}$ Present address: Q Test Labs, Columbus, OH 43235, USA. ${ }^{10}$ Present address: Department of Neurobiology, St Joseph's Hospital and Medical Center-Barrow Neurological Institute, Phoenix, AZ 85013, USA. ${ }^{11}$ Present address: Department of Neurology, Columbia University Medical Center, New York, NY 10032, USA. ${ }^{12}$ Present address: Department of Biomedical Engineering and Pediatrics, Emory University, Decatur, GA 30322, USA. ${ }^{13}$ Present address: Bristol-Myers Squibb, Wallingford, CT 06492, USA. ${ }^{14}$ Present address: Molecular Oncology Research Institute, Tufts Medical Center, Boston, MA 02111, USA. ${ }^{15}$ Present address: Department of Genetics and Genome Sciences, Case Western Reserve University, Cleveland, OH 44106, USA. ${ }^{16}$ Present address: Children's Hospital of Philadelphia, Philadelphia, PA 19104, USA. Correspondence and requests for materials should be addressed to D.C.G. (email: guttridg@musc.edu)
} 


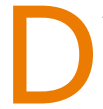
ystrophin is a large cytoplasmic protein that provides structural integrity to muscle. Mutations in the dystrophin gene result in X-linked dilated cardiomyopathy, Becker muscular dystrophy, and Duchenne muscular dystrophy $(\mathrm{DMD})^{1-3}$. Loss of dystrophin protein has also been reported in acquired heart failure, myocardial infection, and myocardial infarction patients, as well as in animal models of myocardial injury and infection ${ }^{4-8}$. This suggests that downstream effects of dystrophin loss is a common link in cardiomyopathy. In DMD patients and animal models, limb, diaphragm, and cardiac muscles are all progressively affected, resulting in loss of ambulation, respiratory distress, and cardiomyopathy, respectively. Cardiac involvement in patients begins in the second to third decade of life and is a leading cause of morbidity and mortality ${ }^{9}$. These patients commonly develop cardiomyopathy with arrhythmias, and animal studies show that calcium dysregulation is a causative factor in the pathology ${ }^{10,11}$. However, the molecular mechanisms underlying disease development in these patients have not been elucidated, and the acute cardiac events that lead to an accumulation of cardiac damage are not well understood.

$\mathrm{NF}-\kappa \mathrm{B}$ is ubiquitously expressed and functions in cell survival, apoptosis, growth, and differentiation ${ }^{12}$. Our group and others have shown that NF- $\mathrm{BB}$ signaling regulates both physiological (differentiation, growth, and metabolism) and pathophysiological (cachexia, atrophy, and dystrophy) aspects of skeletal muscle biology ${ }^{13-16}$. The most common NF- $\kappa B$ complex is the $\mathrm{p} 50 / \mathrm{p} 65$ heterodimer, with p65 containing the transactivation domain required to mediate transcriptional activation. NF- $\kappa \mathrm{B}$ is held in tight regulation by the inhibitory protein I $\kappa$ B. The upstream IKK kinase (inhibitor of NF- $\kappa \mathrm{B}$ kinase) is comprised of two catalytic subunits, IKKa and IKK $\beta$, and a regulatory subunit, IKK $\gamma /$ NEMO. During classical NF- $\kappa B$ activation, IKK is phosphorylated, and in turn phosphorylates $\mathrm{I} \kappa \mathrm{B}$. This phosphorylation causes ubiquitination and subsequent degradation of $\mathrm{I} \kappa \mathrm{B}$ by the $26 \mathrm{~S}$ proteasome pathway. Degradation of I $\mathrm{B}$ unmasks a nuclear localization site, allowing NF- $\mathrm{BB}$ to translocate to the nucleus, bind consensus sites on target genes, and activate gene expression.

Studies show that classical NF- $\kappa$ B promotes skeletal muscle pathology in the $m d x$ murine DMD model ${ }^{17-21}$. Inhibiting NF$\kappa \mathrm{B}$, either globally by ablating one copy of the p65 gene or conditionally by removing IKK $\beta$ alleles in skeletal muscle fibers or myeloid cells, improved dystrophic pathology ${ }^{18}$. Cell or gene therapy designed to target p65 or IKK, respectively, were also effective in protecting $m d x$ skeletal muscle ${ }^{19-21}$. Mechanistically, inhibiting NF- $\kappa \mathrm{B}$ improved the histology and function of dystrophic limb and diaphragm muscles by enhancing the regenerative potential of muscle stem cells and reducing muscle damage from inflammatory cells ${ }^{18}$. These findings laid the foundation for inhibiting NF- $\mathrm{BB}$ as a therapy to treat DMD.

As a therapeutic, we and others have examined the potential of using the Nemo Binding Domain (NBD) peptide, which is a specific $\mathrm{NF}-\mathrm{kB}$ inhibitor ${ }^{22}$. In $m d x$ mice, NBD treatment rescued diaphragm function and improved overall muscle endurance ${ }^{17,18}$. Histologically, NBD reduced inflammation and enhanced regeneration in limb muscles, indicating dystrophic muscles were stabilized. In the Golden Retriever DMD model (GRMD), NBD administration improved hind-limb function, posture, and skeletal muscle histopathology ${ }^{23}$. While encouraged that such results might translate to improved ambulation and respiratory function in DMD patients, we realized that further development of an NF- $\mathrm{B}$ inhibitor would require investigation into its effects on dystrophic cardiac muscle. In a preliminary study, we showed that NBD administration rescued in vitro cardiac function in the severe dystrophin/utrophin double knockout murine DMD model ${ }^{24}$. These results indicated that NF- $\kappa \mathrm{B}$ contributes to dystrophic cardiac disease, but how it promotes this pathology remains unknown.
In this study, we set out to understand the mechanism by which NF- $\kappa \mathrm{B}$ regulates cardiac dysfunction in $m d x$ mice. We discover that unlike the typical function of NF- $\kappa \mathrm{B}$ as an inducer of gene expression, NF- $\mathrm{kB}$ ablation in $m d x$ cardiomyocytes causes global permissive chromatin remodeling on enhancers of calcium genes, which in turn permits increased gene expression and an overall improvement in cardiac function.

\section{Results}

NF- $\kappa B$ promotes cardiac dysfunction in $m d x$ mice. Cardiomyopathy develops progressively over the lifespan of the $m d x$ mouse. From a young age (8-10 weeks), only ex vivo cardiomyocyte dysfunction is detected ${ }^{25,26}$. Histological abnormalities are apparent by 7 months ${ }^{27}$, and by 10-12 months, dysfunction in vivo is detectable by echocardiogram ${ }^{28-30}$. By 2 years, severe cardiomyopathy is apparent ${ }^{31}$. Based on these time points, we asked if NF- $\kappa \mathrm{B}$ activation occurs early in the disease process. NF$\kappa \mathrm{B}$ DNA binding was low in 3-month-old adult wt hearts, and increased in age matched $m d x$ hearts (Fig. 1a). This activity was attributable to p65 and p50 (Fig. 1a). Phosphorylation of p65 on serine 536, which is a marker of NF- $\kappa \mathrm{B}$ transcriptional activity, indicated that NF- $\kappa \mathrm{B}$ activation persisted in 1-year-old $m d x$ hearts (Fig. 1b). To determine the cellular source of NF- $\kappa B$, we performed immunohistochemistry on cardiac tissue. Results showed that NF- $\kappa \mathrm{B}$ was most prominently localized to $m d x$ cardiomyocyte nuclei (Fig. 1c and Supplementary Fig. 1A). Together, these results indicate that NF- $\mathrm{KB}$ is active prior to the onset of $m d x$ cardiomyopathy, and persists throughout the disease process.

Since we detected activated NF- $\kappa \mathrm{B}$ within cardiomyocytes, we asked if this signaling was relevant for dystrophic cardiomyopathy by conditionally deleting IKK $\beta$ from $m d x$ cardiomyocytes. Knock-out mice were denoted $m d x^{\mathrm{HRT} \Delta \mathrm{IKK} \beta}$, while littermates with intact NF- $\kappa \mathrm{B}$ were designated $m d x^{\mathrm{IKK} \beta \mathrm{f} / \mathrm{f}}$. We confirmed that IKK $\beta$ expression was reduced in $m d x^{\mathrm{HRT} \Delta \mathrm{IKK} \beta}$ hearts (Supplementary Fig. 1B). Then we examined gross differences between wt, $m d x^{\mathrm{IKK} \beta \mathrm{f} / \mathrm{f}}$ and $m d x^{\mathrm{HRT} \Delta \mathrm{IKK} \beta}$ mice. Representative histological whole hearts sections are included in Supplementary Fig. 1C. By 12-14 months, body weight and heart weight adjusted for tibia length from both $m d x^{\mathrm{IKK} \beta \mathrm{f} / \mathrm{f}}$ and $m d x^{\mathrm{HRT} \Delta \mathrm{IKK} \beta}$ mice were less than wt, but this difference only reached significance in the $m d x^{\mathrm{HRT} \Delta \mathrm{IKK} \beta}$ mice (Table 1). These data indicate that cardiomyocyte deletion of IKK $\beta$ does not prevent the reduction of body or heart weight that occurs in aging $m d x$ mice 30,32 .

In vivo dysfunction has been shown at 10 months in $m d x$ mice $^{28-30}$. We asked if deleting NF- $\mathrm{BB}$ from $m d x$ cardiomyocytes resulted in long-term functional changes. To assure we could detect differences from control mice, echocardiograms were performed on 13-14 month old mice. While cardiac output was reduced in $m d x^{\mathrm{IKK} \beta \mathrm{f} / \mathrm{f}}$ mice, it was restored to wt levels in $m d x^{\mathrm{HRT} \Delta \mathrm{IKK} \beta}$ mice (Fig. 1d). Because anesthetized heart rates were similar between groups (Table 1), stroke volume, which was also significantly compromised in $m d x^{\mathrm{IKK} \beta \mathrm{f} / \mathrm{f}}$ mice, was restored to wt values in $m d x^{\mathrm{HRT} \Delta \mathrm{IKK} \beta}$ mice (Fig. 1e). Ejection fraction was preserved in $m d x^{\mathrm{IKK} \beta \mathrm{f} / \mathrm{f}}$ mice (Fig. 1f), suggesting that $m d x$ mice suffer from diastolic dysfunction with either preserved systolic function or a compensation that masks systolic dysfunction. A closer analysis of chambers parameters further supported these findings. While systolic diameters and volumes were not significantly altered (Table 1), end diastolic diameters and volumes were both reduced in $m d x^{\mathrm{IKK} \beta \mathrm{f} / \mathrm{f}}$ and normalized in $m d x^{\mathrm{HRT} \Delta \mathrm{IKK} \beta}$ mice (Fig. 1g,h), indicating that NF- $\mathrm{BB}$ deletion prevented the developed pathology of small cardiac chambers in $m d x$ mice. Together, data suggest that in $m d x$ cardiomyocytes, $\mathrm{NF}-\kappa \mathrm{B}$ activation causes a smaller, stiff left ventricle with decreased compliance. 
a
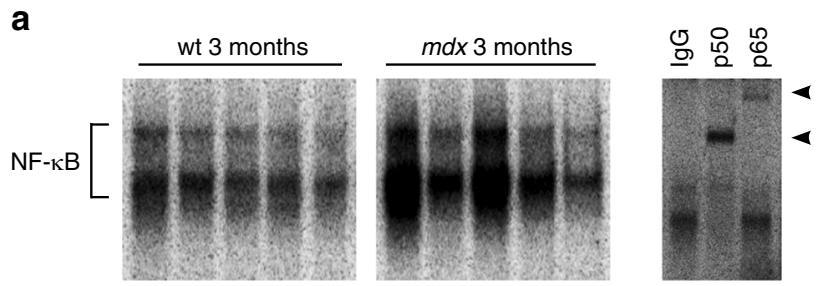

C
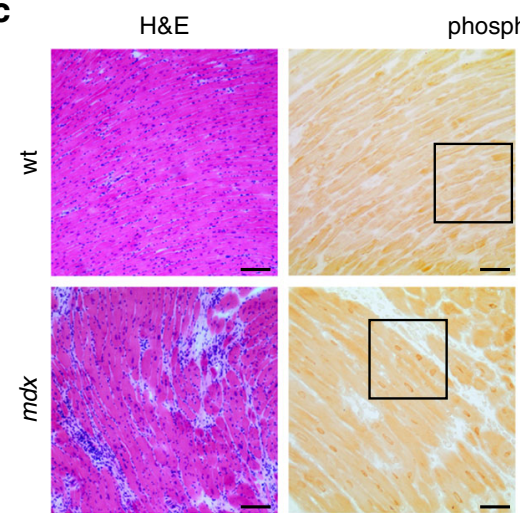

f
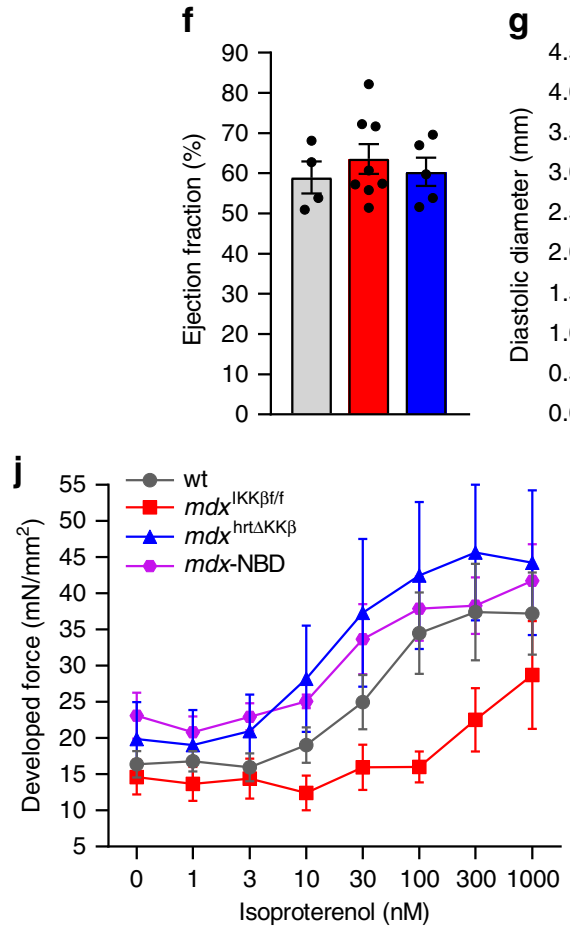

b

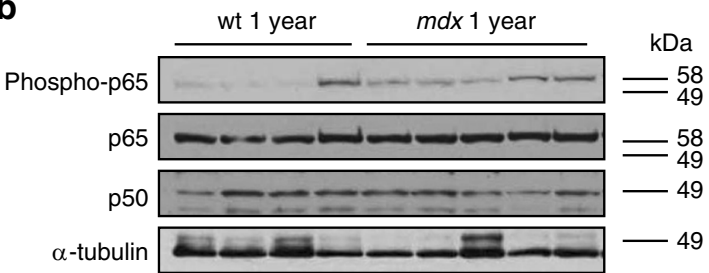

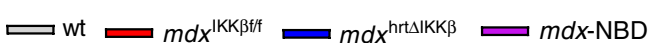

d

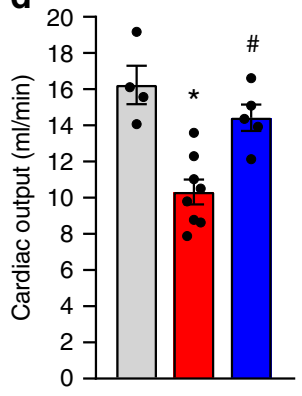

e

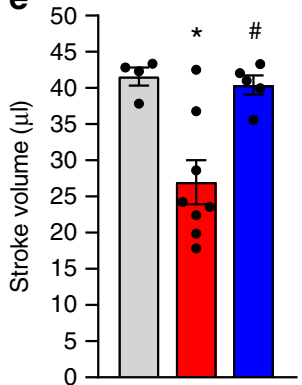

h
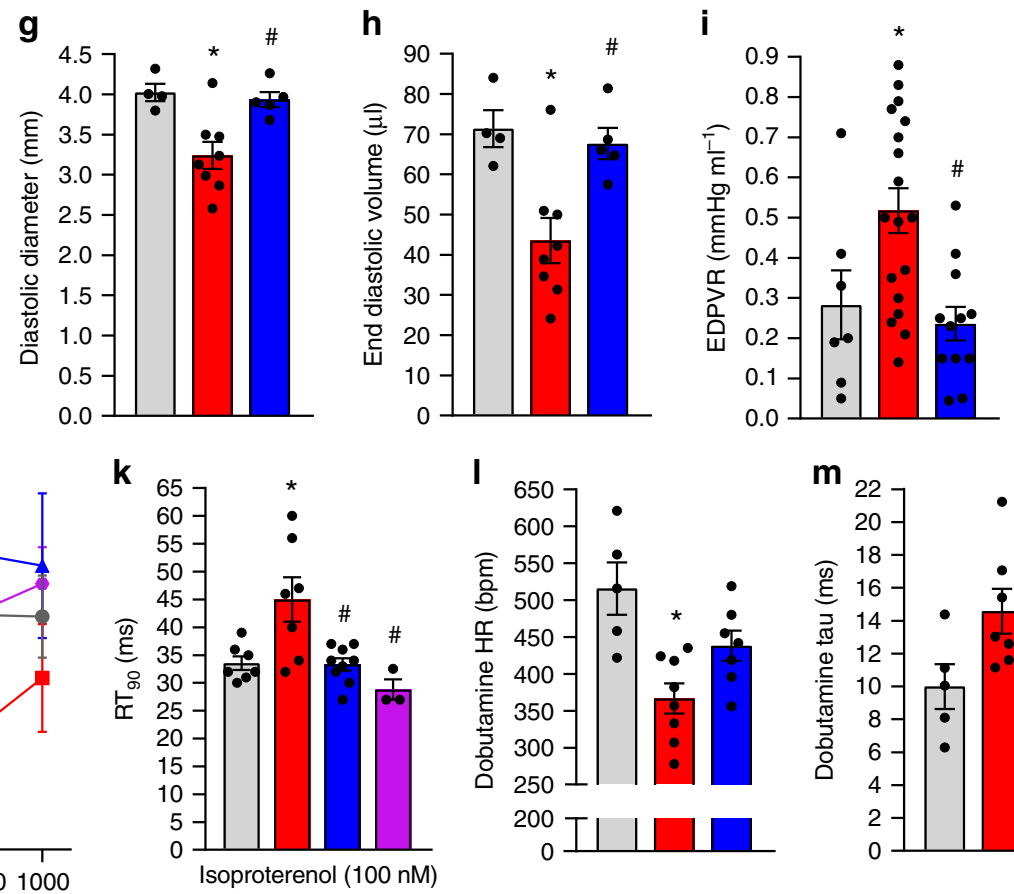

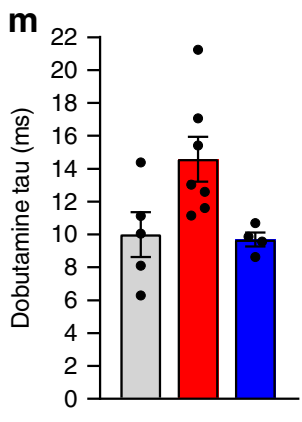

Fig. $1 \mathrm{NF}-\kappa B$ causes heart dysfunction in $m d x$ mice. a EMSA performed on wild-type (wt) and $m d x$ hearts (left panel). Supershift EMSA performed on $m d x$ hearts using specific antibodies for p65 and p50, and IgG as a control (Right panel). Arrowheads indicate shifted bands. b Western blots performed on whole heart lysates and probed for phosphorylated p65-ser536 (phospho-p65), p65, p50, and $\alpha$-tubulin (used as a loading control). c Representative images of H\&E and phosho-p65 staining prepared from 1-year old heart sections. Boxed regions appear as magnified images in neighboring panels. Scale bar $=50 \mu \mathrm{m}$. $\mathbf{d}$ cardiac output, e stroke volume, $\mathbf{f}$ ejection fraction $(p=0.686)$, $\mathbf{g}$ end diastolic diameter, and $\mathbf{h}$ end diastolic volume assessed by

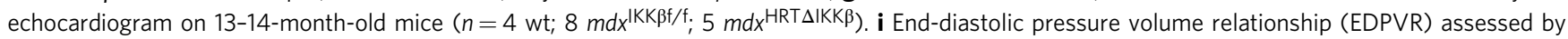
ventricular pressure-volume relationship analysis on 13-14-month old mice ( $n=7 \mathrm{wt} ; 18 \mathrm{mdx}$ IKK $\mathrm{kf} / \mathrm{f} ; 12 \mathrm{mdx}$ HRT $\Delta$ IKK $\beta$ ). j Developed force measured from isolated multicellular cardiac muscles of 7-month old mice in response to $\beta$-adrenergic stimulation with isoproterenol $(n=7 \mathrm{wt} ; 7 \mathrm{mdx} / \mathrm{KK} \beta \mathrm{f} / \mathrm{f} ; 9$ $m d x$ HRT $\Delta$ IKK $; 3$ NBD treated $(m d x-N B D) ; p=0.278)$. $\mathbf{k}$ Relaxation time (RT 90 ) after isoproterenol stimulation in multicellular cardiac muscles $(n=$ same as J). I, $\mathbf{m}$ Ventricular pressure-volume relationship measurements after dobutamine administration on 13-14-month-old mice. I Maximal heart rate (HR)

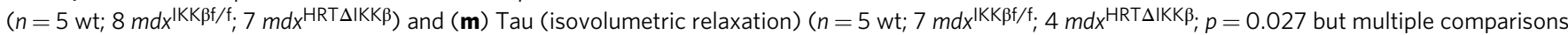
test did not detect differences between groups). Data expressed as means \pm SEM with bars and plungers and individual data points with dots. ${ }^{*} p<0.05$ relative to wt and \# $p<0.05$ relative to $m d x^{1 K K \beta f / f}$ by $\mathbf{d}-\mathbf{i}, \mathbf{k}-\mathbf{m}$ 1-way ANOVA followed by Tukey multiple comparison test where appropriate, $\mathbf{j} 2$-way repeated measures ANOVA. Main effects for genotype/treatment 
Table 1 Data are expressed as means \pm SEM. 1-way ANOVA followed by Tukey multiple comparison test

\begin{tabular}{|c|c|c|c|c|}
\hline Body weight $(\mathrm{g})$ & $36.1 \pm 0.7$ & $33.5 \pm 1.1$ & $31.1 \pm 1.5^{\mathrm{a}}$ & 0.0376 \\
\hline Echocardiogram & $n=4$ & $n=8$ & $n=5$ & \\
\hline $\mathrm{HR}(\mathrm{BPM})$ & $389.8 \pm 17.7$ & $396.1 \pm 21.1$ & $357.0 \pm 13.1$ & 0.3666 \\
\hline Systolic diameter (mm) & $2.8 \pm 0.2$ & $2.2 \pm 0.2$ & $2.7 \pm 0.2$ & 0.0403 \\
\hline End systolic volume (ml) & $29.8 \pm 4.6$ & $16.5 \pm 3.1$ & $27.3 \pm 3.8$ & 0.0432 \\
\hline
\end{tabular}

To more closely investigate how NF- $\kappa \mathrm{B}$ signaling affects cardiac contractility, we performed left ventricular pressurevolume relationship analysis. End-diastolic pressure volume relationship was increased in $m d x^{\mathrm{IKK} \beta \mathrm{f} / \mathrm{f}}$ compared to wt mice and restored to wt values in $m d x^{\mathrm{HRT} \Delta \mathrm{IKK} \beta}$ mice (Fig. 1i), whereas end systolic pressure volume relationship was similar between all groups (Supplementary Table 1). Additional functional parameters that were not significantly altered are also reported in Supplementary Table 1. These data further support our echocardiogram results, suggesting that NF- $\mathrm{BB}$ signaling in $m d x$ cardiomyocytes promotes diastolic dysfunction.

We next examined ex vivo cardiac function. We systemically treated 6-month-old $m d x$ mice with NBD peptide for 1 month and performed function on multicellular cardiac preparations. We chose this time because ex vivo histological and functional cardiac deficits begin to develop at this stage. Age matched mice from our genetic model were used for comparisons. Although force values derived from $m d x^{\mathrm{IKK} \beta \mathrm{f} / \mathrm{f}}$ mice were consistently lower across all frequencies compared to wt, these differences did not reach statistical significance (Supplementary Fig. 1D). In comparison, force production was higher in both $m d x^{\mathrm{HRT} \Delta \mathrm{IKK} \beta}$ and NBD-treated $m d x$ muscles than in $m d x^{\mathrm{IKK} \beta \mathrm{f} / \mathrm{f}}$ and $\mathrm{wt}$ muscles. We then assessed the ability of these multicellular muscles to relax, which affects cardiac diastole. Time from peak force to $90 \%$ relaxation $\left(\mathrm{RT}_{90}\right)$ trended toward being slower in $m d x^{\mathrm{IKK} \beta \mathrm{f} / \mathrm{f}}$ muscles, whereas $m d x^{\mathrm{HRT} \Delta \mathrm{IKK} \beta}$ and $m d x$-NBD muscles showed relaxation times more similar to wt rates (Supplementary Fig. 1E). One indicator of a failing heart is the inability to respond to $\beta$-adrenergic stimulation ${ }^{33}$. We tested if this was dependent on NF- $\kappa \mathrm{B}$ signaling. When cardiac muscles were challenged with increasing doses of the $\beta$-adrenergic stimulant isoproterenol, $m d x^{\mathrm{IKK} \beta \mathrm{f} / \mathrm{f}}$ cardiac preparations responded with weak force production characteristic of their dystrophic phenotype (Fig. $1 \mathrm{j})^{26}$. These mice were unresponsive to both low and moderate isoproterenol doses, only responding with slightly increased force production at high doses. In contrast, $m d x^{\mathrm{HRT} \triangle \mathrm{IKK} \beta}$ and NBD-treated $m d x$ cardiac preparations responded to low isoproterenol doses following a parabolic curve similar to wt muscles. When we assessed relaxation, in response to isoproterenol, time from peak force to $90 \%$ relaxation $\left(\mathrm{RT}_{90}\right)$ was slower in $m d x^{\mathrm{IKK} \beta \mathrm{f} / \mathrm{f}}$ muscles, whereas $m d x^{\mathrm{HRT} \Delta \mathrm{IKK} \beta}$ and NBD-treated $m d x$ cardiac preparations showed an improved ability to accelerate their relaxation time back to wt levels (Fig. 1k). Together, these results indicate that pharmacological inhibition of NF- $\mathrm{kB}$ for just 1 month can reverse existing, stress induced cardiac muscle dysfunction, and that inhibition of NF- $\kappa B$ systemically and specifically in cardiomyocytes reverses the pathological inability of cardiac muscle preparations to respond to $\beta$-adrenergic stimulation.

To further explore the inability of $m d x$ mice to respond to $\beta$ adrenergic stimulation, and the dependency of this response on cardiomyocyte NF- $\kappa \mathrm{B}$, we challenged mice with the $\beta$-adrenergic agonist dobutamine while performing pressure-volume loop analysis in vivo. Wt mice responded with a robust increase in heart rate, while $m d x^{\mathrm{IKK} \beta \mathrm{f} / \mathrm{f}}$ mice were unable to increase their heart rates (Fig. 11). $m d x^{\mathrm{HRT} \Delta \mathrm{IKK} \beta}$ mice responded with an increased heart rate, but did not normalize to wt. Isovolumetric relaxation time (tau) indicated that accelerated relaxation occurred in wt and $m d x^{\mathrm{HRT} \Delta \mathrm{IKK} \beta}$, but not in $m d x^{\mathrm{IKK} \beta \mathrm{f} / \mathrm{f}}$ mice, although this did not reach significance (Fig. 1m). These data demonstrate that $m d x$ cardiac muscle have an impaired ability to relax and are therefore unable to respond to $\beta$-adrenergic stress with heart rate acceleration. Cumulatively, data show that cardiomyocyte NF- $\mathrm{kB}$ impairs cardiac response to $\beta$-adrenergic stress, thus providing the first evidence that cardiomyocytederived classical NF- $\mathrm{kB}$ signaling plays an instrumental role in promoting dystrophic cardiac dysfunction. Although we cannot exclude the possibility that alternative NF- $\kappa \mathrm{B}$ is compensating for the loss of IKK $\beta$ and contributing to the improved phenotype, processing of $\mathrm{p} 100$ to $\mathrm{p} 52$, as a measure of alternative pathway activation, was undetectable in the hearts of any of our mice (Supplementary Fig. 1F).

Cardiomyocyte NF-kB inhibition improves calcium handling in $\boldsymbol{m d x}$ hearts. Because cardiac stiffness from fibrosis leads to diastolic dysfunction, and expression of fibrotic genes is increased at an early age in $m d x$ hearts (Supplementary Fig. 2A), we asked if $\mathrm{NF}-\kappa \mathrm{B}$ promoted cardiac fibrosis. Histologically, fibrosis was comparable in hearts from 1-year-old $m d x^{\mathrm{IKK} \beta \mathrm{f} / \mathrm{f}}$ and $m d x x_{\text {HRT } \triangle \mathrm{IKK} \beta}$ mice (Supplementary Fig. $2 \mathrm{~B}, \mathrm{C}$ ). This finding was consistent with gene expression analysis of the same panel of fibrotic genes that were elevated in $m d x$ mice (Supplementary Fig. 2D). Membrane disruption also appeared similar between groups (Supplementary Fig. 2B). These data led to an intriguing implication that while cardiomyocyte $\mathrm{NF}-\kappa \mathrm{B}$ is not required for development of cardiac fibrosis or myocyte injury in $m d x$ mice, it still contributes to cardiac dysfunction.

To gain insight into how NF- $\mathrm{BB}$ promotes cardiomyocyte dysfunction, we performed microarray analysis comparing $m d x^{\mathrm{HRT} \Delta \mathrm{IKK} \beta}$ to $m d x^{\mathrm{IKK} \beta \mathrm{f} / \mathrm{f}}$ hearts. Gene Ontology $(\mathrm{GO})$ and Kyoto Encyclopedia of Genes and Genomes (KEGG) pathway annotations identified genes related to calcium as enriched in the absence of NF-kB (Fig. 2a). Because of this proposed link between NF- $\mathrm{KB}$ and calcium, we examined calcium transient amplitudes at the single cell level to determine if gene expression changes coincided with functional outcomes. Results showed that calcium transients were reduced in $m d x^{\mathrm{IKK} \beta \mathrm{f} / \mathrm{f}}$ compared to wt mice (Fig. 2b). In sharp contrast, calcium transient deficits were rescued in $m d x$ HRT $\triangle$ IKK $\beta$ cardiomyocytes, indicating that $\mathrm{NF}-\kappa \mathrm{B}$ is intrinsically regulating calcium handling in $m d x$ cardiomyocytes. 

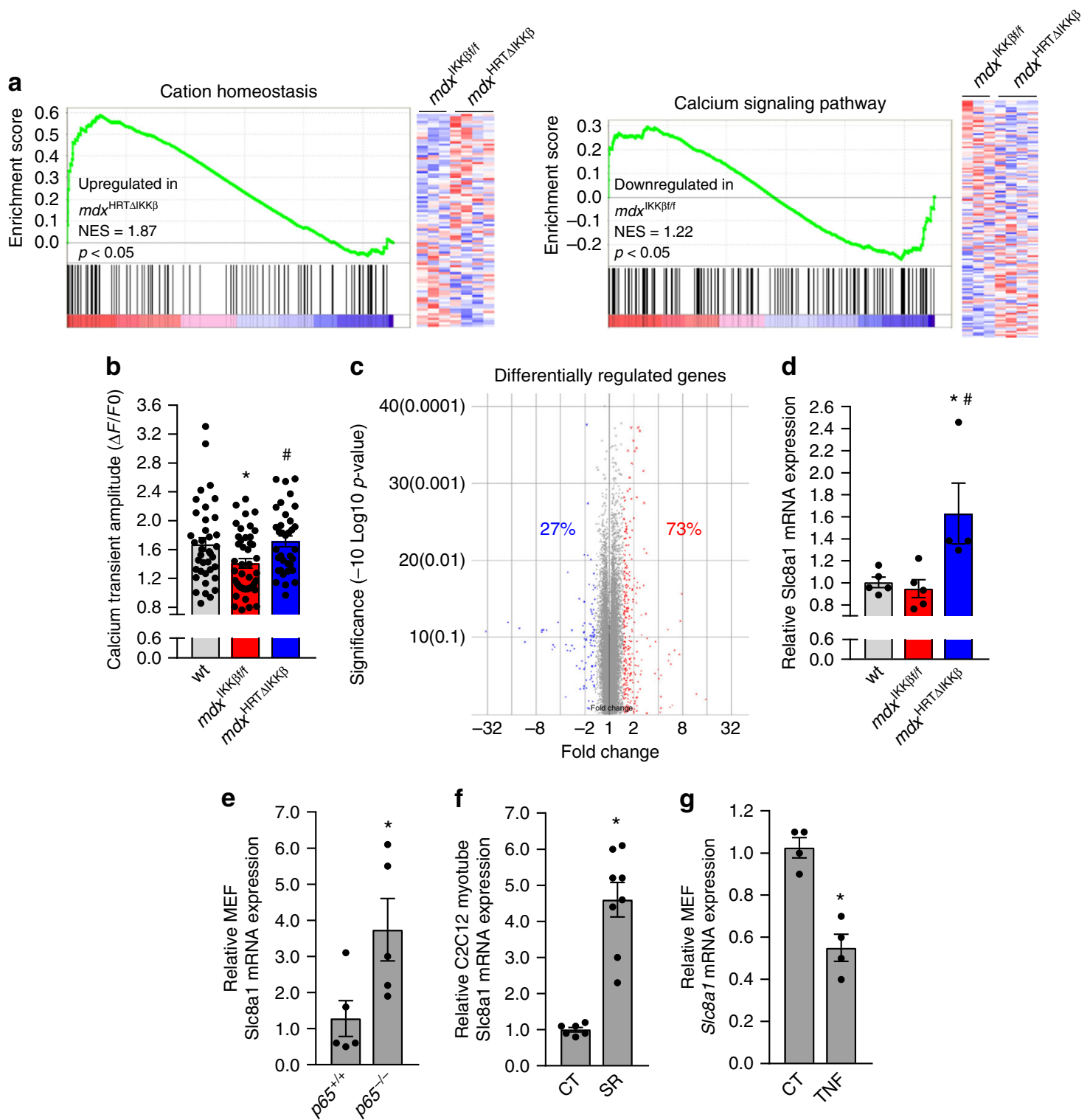

Fig. 2 Cardiomyocyte NF- $\mathrm{\kappa B}$ ablation normalizes calcium handling and increases gene expression. a Statistically significant gene categories from microarray analysis identified using Gene Set Enrichment Analysis. Heatmaps represent genes identified in annotations. b Calcium transient amplitude measured from cardiomyocytes isolated from 7-8-month old mice ( $n=38$ wt; $43 \mathrm{mdx}$ IKK $\mathrm{Kf} / \mathrm{f} ; 35 \mathrm{mdx}{ }^{\mathrm{HRT} \Delta \mathrm{IKK} \beta}$ cardiomyocytes). c Depiction of individual microarray genes that were up- and down-regulated in $m d x^{H R T \Delta I K K \beta}$ relative to $m d x^{1 K K \beta f / f}$ hearts. Genes shown in red are $\geq 1.5$-fold upregulated and those in blue are $\geq 1.5$-fold downregulated. $\mathbf{d}$-g qPCR analysis of S/c8a1 expression. RNA isolated from $\mathbf{d}$ 6-7-month-old hearts ( $n=5 \mathrm{wt} ; 5 \mathrm{mdx}{ }^{\mathrm{IKK} \beta \mathrm{f} / \mathrm{f} ;} 4$ $\left.m d x^{H R T \Delta I K K \beta}\right)$, e mouse embryonic fibroblasts (MEFs) that were wt $\left(p 65^{+/+}\right)$or null $\left(p 65^{-/-}\right)$for $p 65(n=5)$. f $\mathrm{C} 2 \mathrm{C} 12$ myotubes expressing empty vector as control (CT) or I $\mathrm{kB} \alpha$ super repressor (SR) $(n=6 \mathrm{CT} ; 8 \mathrm{SR})$, and $\mathbf{g}$ MEFs untreated (CT) or treated with TNF $(n=4)$. Data expressed as means \pm SEM with bars and plungers and individual data points with dots. ${ }^{*} p<0.05$ relative to respective control and \#p $<0.05$ relative to $\mathrm{mdx}{ }^{\mathrm{IKK} \beta \mathrm{f} / \mathrm{f}}$ by $\mathbf{b}, \mathbf{d} 1$-way ANOVA followed by Tukey multiple comparison test and $\mathbf{e}-\mathbf{g}$ 2-tailed Student's $t$ test

We then took a broader look at the overall gene expression pattern of dystrophic hearts lacking NF-kB to gain a better understanding for how this factor may be regulating calcium. NF$\kappa \mathrm{B}$ dimers containing the p65 subunit are usually thought of as transcriptional activators. Thus, when bound to consensus DNA sequences, target gene expression is typically stimulated ${ }^{12}$. Accordingly, we anticipated an overall reduction in gene expression upon deleting NF- $\mathrm{kB}$ in cardiomyocytes. Surprisingly, only $27 \%$ of differentially regulated genes (using 1.5 -fold cut-off) were downregulated when NF- $\mathrm{kB}$ was deleted, whereas $73 \%$ were upregulated (Fig. 2c). Consistently, the majority of calcium genes identified in the GO and KEGG annotations were also upregulated in $m d x^{\mathrm{HRT} \Delta \mathrm{IKK} \beta}$ hearts (Fig. 2a). This is in sharp contrast to microarray results we recently reported from Ras transformed $p 65^{-1-}$ mouse embryonic fibroblasts (MEFs), which as expected, showed a predominance of down-regulated genes (89\%) compared to $p 65^{+/+}$cells $s^{34}$, or previous results in TNF treated HeLa cells, which demonstrated a similar predominance of NF- $\mathrm{kB}$ dependent upregulated genes ${ }^{35}$. Thus, our findings reveal a previously unappreciated functional role for NF- $\mathrm{KB}$ as a global repressor in $m d x$ hearts.

Next, we sought to understand how NF- $\kappa B$ functions to repress calcium genes. We observed that differential expression was subtle, suggesting that small changes from multiple genes, rather than a large change from a single gene, might be responsible for improvements in calcium handling in the absence of NF- $\kappa B$. We 
searched for candidate genes that were both upregulated in $m d x^{\mathrm{HRT} \Delta \mathrm{IKK} \beta}$ hearts and associated with calcium. One gene that fit these criteria was the solute carrier family 8 (sodium/calcium exchanger), member 1 , (Slc8a1 gene that codes for the NCX1 protein). NCX1 is a transmembrane channel protein that plays a role in maintaining calcium homeostasis in multiple cell types including muscle ${ }^{36}$. Quantitative RT-PCR confirmed Slc8a1 upregulation in $m d x^{\mathrm{HRT} \Delta \mathrm{IKK} \beta}$ compared to $m d x^{\mathrm{IKK} \beta \mathrm{f} / \mathrm{f}}$ hearts (Fig. 2d), suggesting this gene is negatively regulated by NF- $\kappa B$. This regulation was not restricted to cardiac tissue, since similar upregulation occurred in $p 65^{-/-}$compared to $p 65^{+/+}$MEFs and C2C12 skeletal myoblasts stably expressing the IkBa mutant super repressor (SR) inhibitor of NF- $\kappa B$ (Fig. 2e,f). Conversely, whereas TNF typically activates NF- $\mathrm{B}$ to induce gene expression, TNF treatment of both MEF and $\mathrm{C} 2 \mathrm{C} 12$ cells significantly reduced Slc8a1 expression (Fig. 2g and Supplementary Fig. 2E). This response was specific to p65, since Slc8a1 expression was comparable between $p 50^{+/+}$and $p 50^{-1-}$ MEFs (Supplementary Fig. 2F). Collectively, these results support that NF- $\mathrm{\kappa B}$ represses Slc8a1.

NF-kB repression of Slc8a1 occurs through depletion of H3K27ac. We next investigated the mechanism of Slc8a1 repression by NF- $\mathrm{B}$. Our previous studies in skeletal muscle demonstrated that NF- $\kappa B$ repressed myofibrillar genes through activation of the Polycomb chromatin remodeling complex associated protein, YY1 ${ }^{37,38}$. However, no significant difference in Yy1 expression was detected between $m d x^{\mathrm{HRT} \Delta \mathrm{IKK} \beta}$ and $m d x^{\mathrm{IKK} \beta \mathrm{f} / \mathrm{f}}$ hearts (Supplementary Fig. $3 \mathrm{~A}$ ), suggesting that NF$\kappa \mathrm{B}$ does not utilize $\mathrm{YY} 1$ to repress gene expression in cardiomyocytes. To explore the possibility of an alternative chromatin remodeling mechanism, we used the UCSC Genome Browser to examine the chromatin landscape of Slc8a1. Results identified a putative regulatory region within the first intron containing a CpG island (Fig. 3a). In addition to regulating genes through DNA methylation, CpG islands influence chromatin conformation. Accordingly, we found the $\mathrm{CpG}$ island embedded in a $3 \mathrm{~kb}$ region, which ENCODE ChIP sequencing (ChIP-seq) datasets also showed were enriched for numerous histone modifications. Based on this information, we examined whether epigenetic and/ or chromatin-mediated mechanisms were regulating Slc8a1 expression by treating MEFs with the pan histone deacetylase inhibitor (HDACi) Trichostatin A (TSA) alone, or in combination with the DNA methylation inhibitor 5-Aza-2'-deoxycytidine (5-Aza). We first confirmed these drugs were effectively preventing histone deacetylation and demethylating DNA, respectively, using the gene, Wifl, which is epigenetically silenced in MEFs. Wif1 was highly induced by the dual treatment of TSA and 5-Aza (Supplementary Fig. 3B). With respect to Slc8a1, TSA increased expression, whereas 5-Aza alone had no effect (Fig. 3b). TSA in combination with 5-Aza did not result in an additional increase over TSA alone. Consistently, TSA increased Slc8a1 expression in HL-1 cardiomyocytes and $\mathrm{C} 2 \mathrm{C} 12$ myoblasts (Fig. 3c, d). Together, these results suggest that NF- $\kappa B$ regulates Slc8a1 through a histone modification-dependent mechanism.

We next performed ChIP assays to look for differences in several histone marks. We examined the acetylation (ac) and trimethylation (me3) of lysine 27 on histone H3 (H3K27). $\mathrm{H} 3 \mathrm{~K} 27 \mathrm{ac}$ and H3K27me3 antagonize one another, indicative of transcriptional activation and repression, respectively. Additionally, we looked for me3 of histone $\mathrm{H} 3$ on lysine 9 (H3K9me3), a mark conducive for transcriptional repression. ChIP results revealed that Slc8a1 was enriched for $\mathrm{H} 3 \mathrm{~K} 27 \mathrm{ac}$ in $p 65^{-1-}$ compared to $p 65^{+/+}$MEFs (Fig. 3e), whereas a loss of enrichment was detected in both H3K27me3 and H3K9me3 (Fig. 3f,g).
H3K27ac enrichment was also detected in C2C12 SR compared to control myoblasts (Fig. 3h). Moreover, ChIP assays revealed that treatment of MEFs with TSA enhanced H3K27ac on Slc8a1 (Fig. 3i). To assess the significance of our results, we performed in vivo ChIPs. Results showed H3K27ac was depleted in $m d x^{\mathrm{IKK} \beta \mathrm{f} / \mathrm{f}}$ hearts, but was normalized in $m d x^{\mathrm{HRT} \Delta \mathrm{IKK} \beta}$ hearts (Fig. 3j). Together these data support that loss of NF- $\kappa B$ signaling in dystrophic cardiomyocytes leads to a more permissive chromatin conformation on Slc8a1.

NF-кB inhibition promotes global H3K27ac enrichment. To determine if $\mathrm{H} 3 \mathrm{~K} 27 \mathrm{ac}$ enrichment on Slc8a1 in the absence of $N F-\kappa B$ was a global event, we performed in vivo ChIP-seq for H3K27ac. Strikingly, $\sim 10,000$ more H3K27ac regions were detected in $m d x^{\mathrm{HRT} \Delta \mathrm{IKK} \beta}$ compared to $m d x^{\mathrm{IKK} \beta \mathrm{f} / \mathrm{f}}$ hearts $(22,498$ vs 12,148$)$, highlighting global transcriptional activation in the absence of NF- $\mathrm{kB}$ signaling, and corroborating our microarray data. Although there were $\sim 10,000$ more individual H3K27ac regions detected in $m d x^{\mathrm{HRT} \Delta \mathrm{IKK} \beta}$ hearts, the genomic landscape of both our samples showed that the largest proportion of bound regions $(\sim 77 \%)$ was within intragenic and distal intergenic regions, which are the expected regions for an enhancer mark such as H3K27ac (Fig. 4a). Further interrogation revealed less than $20 \%$ of $\mathrm{H} 3 \mathrm{~K} 27 \mathrm{ac}$ binding was within $10 \mathrm{~kb}$ of transcriptional start sites (Fig. 4b), substantiating that enrichment was confined mostly to genomic enhancers. To characterize our $\mathrm{H} 3 \mathrm{~K} 27 \mathrm{ac}$ ChIP-seq results in the context of publicly available data sets from the ENCODE Consortium, we examined the genome-wide coverage of $\mathrm{H} 3 \mathrm{~K} 27 \mathrm{ac}, \mathrm{H} 3 \mathrm{~K} 4 \mathrm{me} 1$, and $\mathrm{H} 3 \mathrm{~K} 36 \mathrm{me} 3$ from normal hearts in relationship to our $m d x$ hearts. Whereas ChIP-seq fragment densities peaked around our data with $\mathrm{H} 3 \mathrm{~K} 27 \mathrm{ac}$ and another enhancer mark, H3K4me1, such a spike was absent in fragment densities around peaks with H3K36me3 ChIP-seq data. Instead, consistently elevated fragment densities occurred with H3K36me3, an expected pattern since it marks exons throughout actively transcribed genes (Fig. 4c and Supplementary Fig. 4A). These data indicate the overall binding pattern we observe is consistent with those globally expected in normal hearts.

Because we found that NF- $\kappa \mathrm{B}$ suppresses genome-wide histone acetylation, we suspected that NF- $\mathrm{KB}$ binding would be located near enriched H3K27ac regions. To test this, we analyzed the density of $\mathrm{H} 3 \mathrm{~K} 27 \mathrm{ac}$ binding in our samples across peaks from a publicly available p65 ChIP-seq data set. Results showed that increased $\mathrm{H} 3 \mathrm{~K} 27 \mathrm{ac}$ was detected surrounding p 65 binding peaks in the $m d x^{\mathrm{HRT} \Delta \mathrm{IKK} \beta}$ hearts, even when samples were adjusted to equalize the number of reads per experiment (Fig. $4 \mathrm{~d}$; total reads and Supplemental 4B; equalized reads). Importantly, the slope of the peak was shifted in $m d x^{\mathrm{HRT} \Delta \mathrm{IKK} \beta}$ hearts, reflecting a change in binding around these regions. These subtle differences in the genomic landscape were expected because the observed phenotype was a change in the degree of $\mathrm{H} 3 \mathrm{~K} 27 \mathrm{ac}$, as opposed to a complete abolishment of this activation mark. We confirmed by ChIP that p65 binding was also detected on Slc8a1 (Supplementary Fig. 4C). When differentially enriched $\mathrm{H} 3 \mathrm{~K} 27 \mathrm{ac}$ regions from $m d x^{\mathrm{HRT} \Delta \mathrm{IKK} \beta}$ relative to $m d x^{\mathrm{IKK} \beta \mathrm{f} / \mathrm{f}}$ hearts were queried for significant GO pathways, networks of calcium-related terms were prominent (Fig. 4e). These findings reinforced that in the absence of NF- $\kappa \mathrm{B}$ activation, global H3K27ac is enhanced on calcium genes of $m d x$ hearts.

To validate ChIP-seq results, we selected a subset of calcium genes that were also upregulated in our microarray. These genes were Slc8a1, Rcan1 (regulator of calcineurin 1), Cacna1h (calcium voltage-gated channel subunit alphal $\mathrm{H}$ ), and Camk4 (calcium/ calmodulin dependent protein kinase IV). We confirmed that expression of these genes was upregulated in $m d x^{\mathrm{HRT} \Delta \mathrm{IKK} \beta}$ 
a

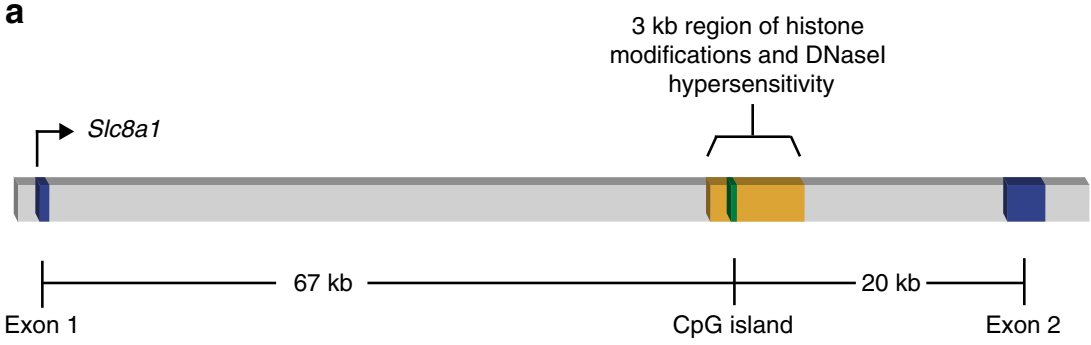

b

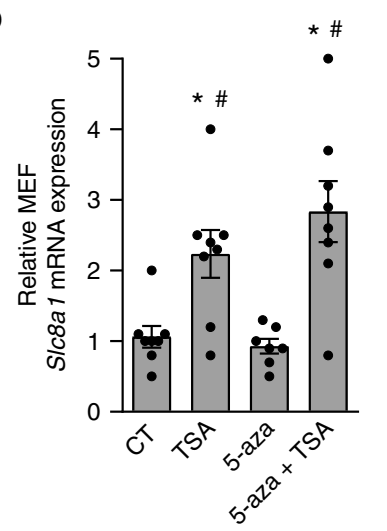

C
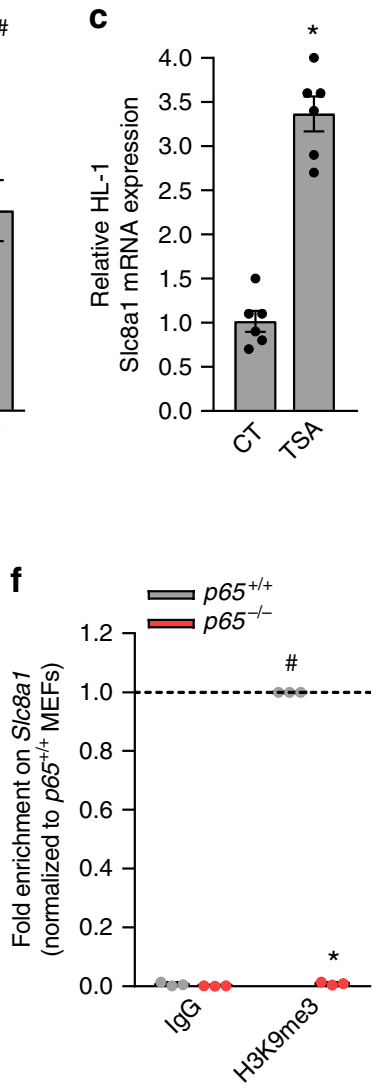

i

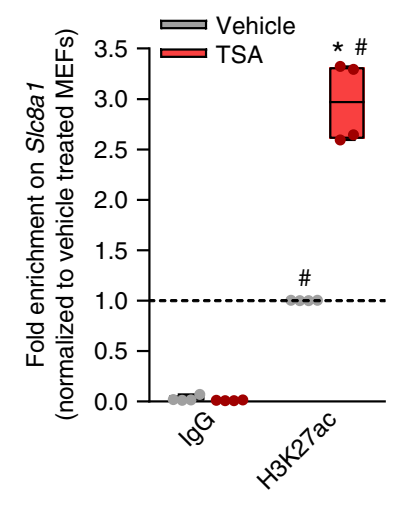

d

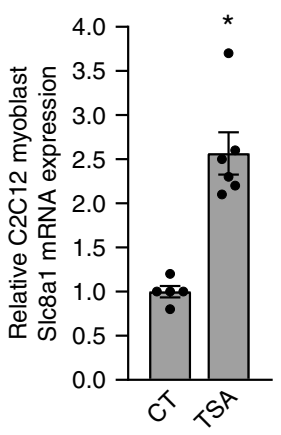

e

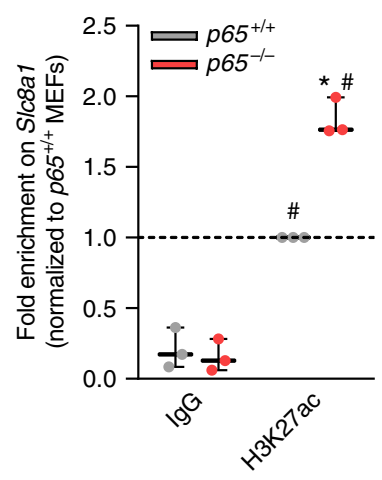

h

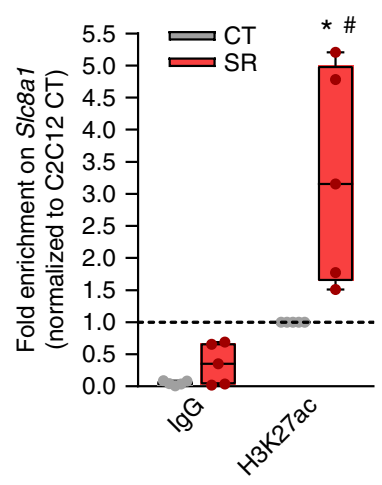

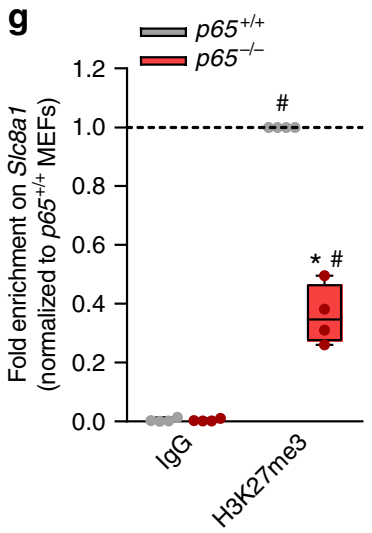

i

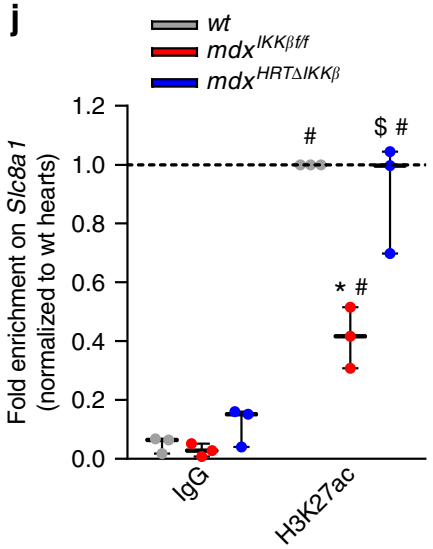

relative to $m d x^{\mathrm{IKK} \beta \mathrm{f} / \mathrm{f}}$ hearts (Fig. $4 \mathrm{f}$ ). Next, ChIP analysis on all four genes showed that $\mathrm{H} 3 \mathrm{~K} 27 \mathrm{ac}$ was enriched in $m d x^{\mathrm{HRT} \Delta \mathrm{IKK} \beta}$ relative to $m d x^{\mathrm{IKK} \beta \mathrm{f} / \mathrm{f}}$ hearts (Fig. $4 \mathrm{~g}$ ). To illustrate the dependency of H3K27ac on NF- $\kappa \mathrm{B}$ activation, we treated MEFs with TNF. Treatment resulted in loss of H3K27ac enrichment (Fig. 4h). Interestingly, analysis of publicly available ChIP-seq data revealed that $\mathrm{p} 65$ peaks were present on all four genes near regions where we detected H3K27ac (Supplementary Fig. 4D).
Together, these results indicate that NF- $\mathrm{BB}$ orchestrates global repression of $\mathrm{H} 3 \mathrm{~K} 27 \mathrm{ac}$ in $m d x$ hearts.

NF-кB inhibition confers permissive chromatin through repressor redistribution. To further explore the mechanism by which NF- $\kappa$ B inhibition regulates expression of calcium genes, we performed a motif analysis using our H3K27ac ChIP-seq from 
Fig. $3 \mathrm{NF}-\kappa \mathrm{B}$ ablation increases S/c8a1 through H3K27ac depletion. a Schematic depicting a regulatory region of interest within intron 1 of S/c8a1. Blue boxes $=$ exons, orange box $=$ the region of interest, green box $=C p G$ island, arrow $=$ TSS. $\mathbf{b}-\mathbf{d}$ S/c8a1 expression analyzed by qPCR on total RNA isolated from b MEFs that were vehicle treated (CT) or treated with trichostatin A (TSA), 5-Aza-2'-Deoxycytidine (5-aza), or a combination of TSA and 5-aza ( $n=8$ except 5 -aza $n=7)$, and $\mathbf{c ~ H L - 1 ~ c a r d i o m y o c y t e s ~}(n=6)$ or $\mathbf{d}$ C2C12 myoblasts treated with vehicle (CT) or TSA and expressed relative to CT expression ( $n$ $=5$ CT; 6 TSA). $\mathbf{e}-\mathbf{j}$ ChIPs performed with $\mathbf{e}, \mathbf{h}-\mathbf{j}$ an H3K27ac antibody, (f) an H3K9me3 antibody $(n=3)$, or $\mathbf{g}$ an H3K27me3 antibody ( $n=4)$ and qPCR analysis was used to detect enrichment in the S/c8a1 regulatory region. DNA extracted from e-g, i MEFs $(n=3 \mathbf{e} ; 4 \mathbf{i}), \mathbf{h}$ C2C12 myoblasts $(n=5)$, or j mouse hearts $(n=3)$. b-d Data expressed as means \pm SEM with bars and plungers and individual data points with dots. $\mathbf{e}-\mathbf{j}$ Data expressed using box and whiskers plots. The central line in the boxes is the median value; the lower and upper boundaries of the boxes represent the lower and upper quartiles, respectively; the lower and upper whiskers represent the minimum and maximum values, respectively. Individual data points are plotted with dots. ${ }^{*} p<0.05$ $\mathrm{CT}$, wt, or vehicle MEF, $\# p<0.055$-aza or $\mathrm{lgG}$, and $\$ p<0.05 \mathrm{mdx} \mathrm{x}^{\mathrm{KK} \text { bf } / \mathrm{f}}$ by $\mathbf{b}$ 1-way ANOVA followed by Tukey multiple comparison test, by $\mathbf{c}$, $\mathbf{d} 2$-tailed Student's $t$ test, or by $\mathbf{e}$-j 2-way ANOVA followed by Tukey Post-hoc analysis

$m d x^{\mathrm{HRT} \Delta \mathrm{IKK} \beta}$ hearts. Due to the vast coverage of acetylated regions, it was difficult to determine other factors that may be interacting locally with $\mathrm{NF}-\kappa \mathrm{B}$. We circumvented this issue by searching for motifs from a data set that included only genes containing both p65 peaks and $\mathrm{H} 3 \mathrm{~K} 27 \mathrm{ac}$ regions. As expected, the motif containing binding sites for the NF- $\kappa B$ family of proteins (Rel Homology Domain; RHD) was the highest ranked motif observed (Fig. 5a). We grouped motifs into families where possible (representative core sequences shown in Fig. 5a) and searched for a candidate repressor protein. The highest ranked repressor motif was CCCTC-binding factor (CTCF). The CTCF protein that binds these motifs is capable of repressing gene expression $^{39}$. To investigate if CTCF was associated with genes repressed in $m d x$ hearts, we ran a filtered list of $\mathrm{H} 3 \mathrm{~K} 27 \mathrm{ac}$ regions associated with genes that were de-repressed in $m d x^{\text {HRTAIKK } \beta}$ hearts. $81 \%$ of the genes containing a CTCF motif were upregulated in $m d x^{\mathrm{HRT} \Delta \mathrm{IKK} \beta}$ hearts (Fig. 5b), indicating that CTCF may be involved in repressing gene expression upon NF- $\kappa \mathrm{B}$ is activation.

Next, we analyzed publically available CTCF ChIP-seq data and compared it to the genome-wide coverage of p65 peaks to investigate the global relationship between p65 and CTCF. Impressively, p65 binding was closely associated with coverage of CTCF, demonstrating that p65 and CTCF are mutually bound to many gene loci (Fig. 5c). When CTCF fragment densities around NF- $\kappa \mathrm{B}$ peak centers were evaluated based on the presence of NF- $\mathrm{B}$ motifs, we found approximately 2-fold higher sequenced fragments from the CTCF data around peaks lacking canonical NF- $\kappa$ B binding sites (Fig. $5 \mathrm{~d}$ ). This more prominent association between CTCF and non-canonical p65 binding was not due to a greater number of total p65 peaks, since noncanonical peaks were still found near CTCF peaks after a random normalization for the number of peaks between the two groups was performed (Supplementary Fig. 5A).

ChIPs confirmed enriched occupancy of CTCF at sites close to the enriched H3K27ac region in $m d x$ hearts on Slc8a1, Rcan1, Cacnalh, and Camk4 (Fig. 5e). Importantly, CTCF occupancy was depleted in $m d x^{\mathrm{HRT} \Delta \mathrm{IKK} \beta}$ relative to $m d x^{\mathrm{IKK} \beta \mathrm{f} / \mathrm{f}}$ hearts, suggesting that CTCF binding was responsive to $\mathrm{NF}-\kappa \mathrm{B}$ inhibition. We then tested CTCF binding in response to NF- $\kappa B$ activation. Corroborating our results in hearts, TNF treatment enriched CTCF binding on all four genes (Fig. 5f). However, no reduction in CTCF binding was observed in $p 65^{-1-}$ compared to p $65^{+/+}$MEFs (Supplementary Fig. 5B), indicating that CTCF binding does not require p65. These results suggest that in response to an inflammatory condition, CTCF regulates chromatin interactions on calcium genes, but this regulation is not directly mediated by NF- $\mathrm{KB}$.

We then asked if repressor complexes known to reduce $\mathrm{H} 3 \mathrm{~K} 27 \mathrm{ac}$ were affected by the loss of p65. In MEFs, SIN3 transcription regulator family member A (SIN3A) and histone deacetylase 1 (HDAC1) showed enrichment in the same regions we detected differences in H3K27ac on Slc8a1, Rcan1, Cacna1h, and Camk4 (Supplementary Fig. 5C, D). Conversely, loss of enrichment occurred in the absence of p65. In $m d x^{\mathrm{IKK} \beta \mathrm{f} / \mathrm{f}}$ hearts, enrichment of SIN3A and HDAC1 was observed on calcium genes (Fig. 5g,h). Except for SIN3A on Cacna1h, this enrichment was diminished in $m d x$ HRT $\triangle \mathrm{IKK} \beta$ hearts. These data suggest that p65 cooperates with chromatin repressors to reduce H3K27ac on calcium genes and limit their expression. To investigate if NF- $\kappa$ B was capable of antagonizing $\mathrm{H} 3 \mathrm{~K} 27 \mathrm{ac}$, we treated HL-1 cardiomyocytes with TSA and TNF. Enhanced gene expression afforded by TSA was diminished by TNF treatment (Fig. 5i). Such data support that upon activation, NF- $\kappa \mathrm{B}$ is capable of antagonizing $\mathrm{H} 3 \mathrm{~K} 27 \mathrm{ac}$, even in the presence of an HDACi. We then asked if the binding of repressor complex members near p65 peaks was a global occurrence. Because our ChIP-seq was performed with $\mathrm{H} 3 \mathrm{~K} 27 \mathrm{ac}$, we used a p65 ChIP-seq data set. The overall binding density of SIN3A and HDAC1 was greater surrounding p65 peaks on genes upregulated in $m d x$ HRT $\Delta \mathrm{IKK} \beta$ hearts (Fig. 5j). Together, these data indicate that in the presence of p65, repressive complexes occupy calcium genes, resulting in a less permissive chromatin conformation.

\section{Discussion}

DMD is a devastating disease that adversely affects both skeletal and cardiac muscles. However, little is known regarding the mechanisms of cardiomyopathy, particularly when it comes to the contribution of individual signaling pathways. Although p38MAPK is aberrantly activated in $m d x$ hearts ${ }^{40}$, the impact of this activation and the identity of other signaling pathways that may contribute to DMD cardiomyopathy have not been explored. Perhaps better understood, is that disruption of calcium homeostasis is considered causative for the pathology of dystrophic hearts ${ }^{10}$. More specifically, a leaky sarcolemma due to the primary loss of dystrophin, activation of calcium leak channels, and alterations in ryanodine receptor channel function, have each been linked to altered calcium concentrations and cellular signaling. However, what causes the alterations in calcium handling proteins and whether reversing these changes rescues dystrophic cardiomyopathy remain unclear.

In this study, we show that inhibiting NF- $\kappa \mathrm{B}$ alleviates cardiac dysfunction in $m d x$ mice by orchestrating global chromatin remodeling to improve calcium signaling. In this respect, we showed that in cardiomyocytes, p65 functions in a different manner than its typical role of directly binding DNA and activating gene expression. Rather, in dystrophic hearts, NF- $\kappa \mathrm{B}$ binds to both its consensus and non-consensus sites, which associates with the enrichment of CTCF on calcium genes. In these same regions, HDAC1 and SIN3A are also enriched, resulting in loss of $\mathrm{H} 3 \mathrm{~K} 27 \mathrm{ac}$ and a less permissive chromatin conformation. In the absence of p65, HDAC1 and SIN3A binding are reduced, resulting in enriched $\mathrm{H} 3 \mathrm{~K} 27 \mathrm{ac}$ and a more permissive chromatin 
a

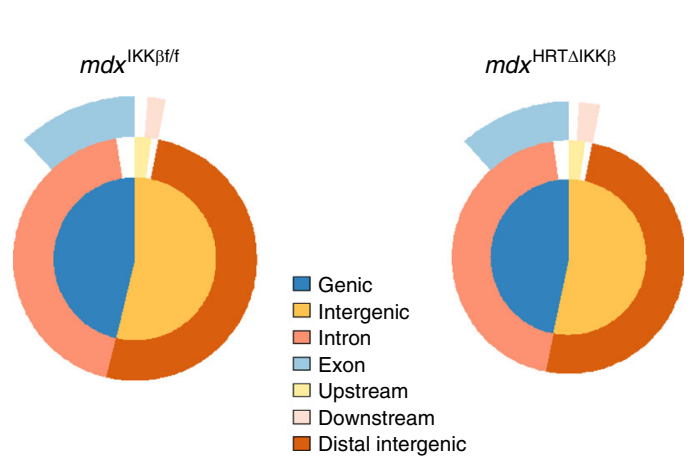

b

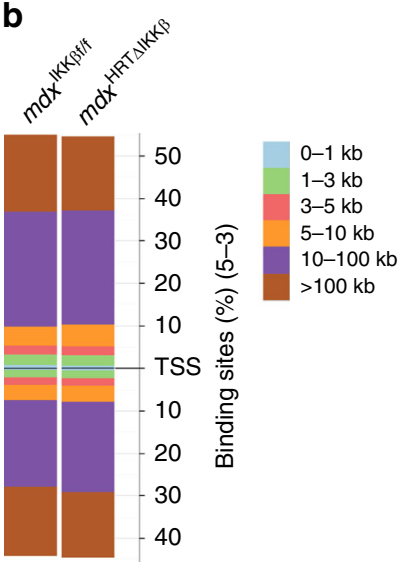

C

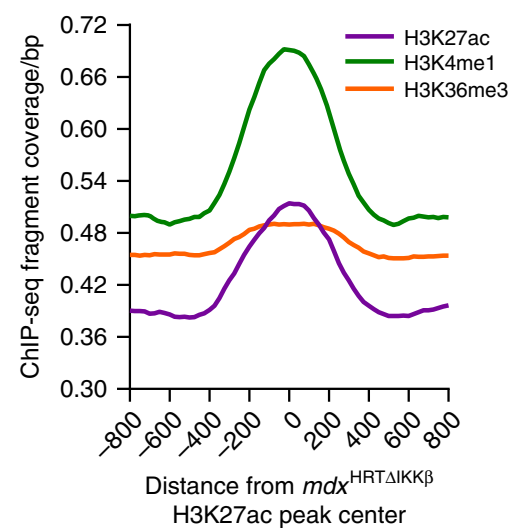

1. Gated channel activity

2. RNA polymerase II transcription factor activity, sequence-specific DNA binding

3. Calcium ion binding

$\square$ 4. Phosphoric ester hydrolase activity

$\square$ 5. Anion transmembrane transporter activity

$\square$ 6. Phosphoric diester hydrolase activity

$\square$ 7. Ligand-gated ion channel activity

8. Phospholipid binding

$\square$ 9. Delayed rectifier potassium channel activity

$\square$ 10. PDZ domain binding

$\square$ 11. Wnt-protein binding

$\square$ 12. Channel regulator activity

$\square$ 13. Calcium-dependent phospholipid binding

14. Receptor signaling protein activity

15. Inorganic anion transmembrane transporter activity

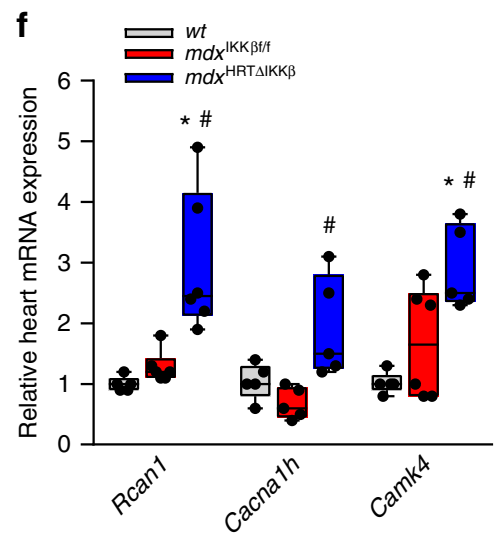

g

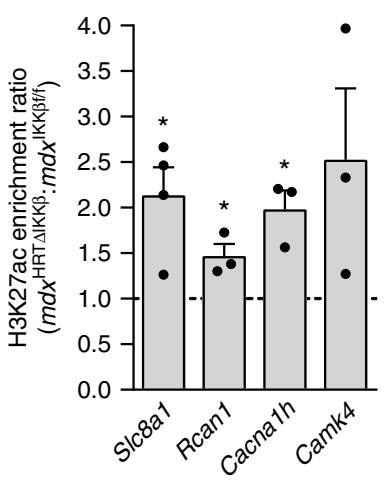

$\mathbf{h}$

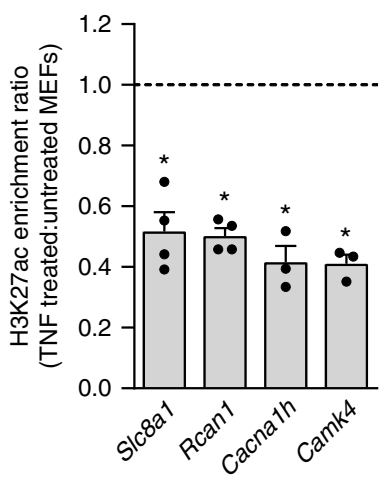

Fig. 4 Cardiomyocyte NF- $\mathrm{KB}$ ablation causes global H3K27ac enrichment in mdx hearts. a Venn diagram pie chart depicting the H3K27ac ChIP-seq annotation within specified regions of the genome from mouse hearts. $\mathbf{b}$ Genome-wide distribution of H3K27ac binding loci relative to transcription start sites (TSS). c-d Genome-wide fragment density showing potential overlap of c. ChIP-seq histone marks across peaks from our ChIP-seg performed in $m d x^{H R T \Delta I K K \beta}$ hearts and $\mathbf{d}$ our ChIP-seqs across peaks from p65 ChIP-seq. e Network showing the top 15 Gene Ontology clusters identified from differentially enriched genes in the $m d x^{\mathrm{HRT} \Delta \mathrm{IKK} \beta}$ when compared to $m d x^{\mathrm{IKK} \beta \mathrm{f} / \mathrm{f}} \mathrm{H} 3 \mathrm{~K} 27$ regions. The most significantly enriched pathway for each cluster is labeled as the representative term for that group. $\mathbf{f}$ Gene expression analyzed by qPCR on total RNA isolated from hearts $(n=R \operatorname{can} 1: 5 \mathrm{wt} ; 6 \mathrm{mdx}$ IKK $\mathrm{kf} / \mathrm{f} ; 6$

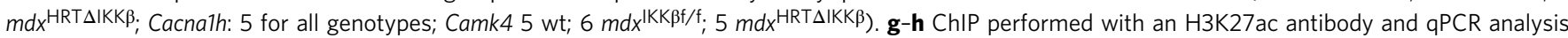
was used to detect enrichment on denoted genes. DNA extracted from $\mathbf{g}$ mouse hearts $(n=3)$ or $\mathbf{h}$ control and TNF treated MEFs $(n=4$ S/c8a1 and Rcan 1 and 3 Cacnalh and Camk4). Genes were expressed as a ratio. Dotted line represents level of enrichment equal to $\mathbf{g} m d x x^{\mathrm{IKK} \beta f / f}$ hearts and $\mathbf{h}$ control MEFs. Bars represent ( $\mathbf{g}$ ) enrichment in hearts and $\mathbf{h}$ depletion in TNF treated MEFs. $\mathbf{f}$ Data expressed using box and whiskers plots. The central line in the boxes is the median value; the lower and upper boundaries of the boxes represent the lower and upper quartiles, respectively; the lower and upper whiskers represent the minimum and maximum values, respectively. Individual data points are plotted with dots. $\mathbf{g}$-h Data expressed as means \pm SEM with bars and plungers and individual data points with dots. $\mathbf{f}^{\star} p<0.05$ wt and $\# p<0.05 \mathrm{mdx}{ }^{\mathrm{IKK \beta f} / \mathrm{f}}$, by 1-way ANOVA followed by Tukey multiple comparison test. g-h ${ }^{\star} p<0.05 m d x^{1 K K \beta f / f}$ or untreated MEFs by 2-tailed Student's $t$ test 

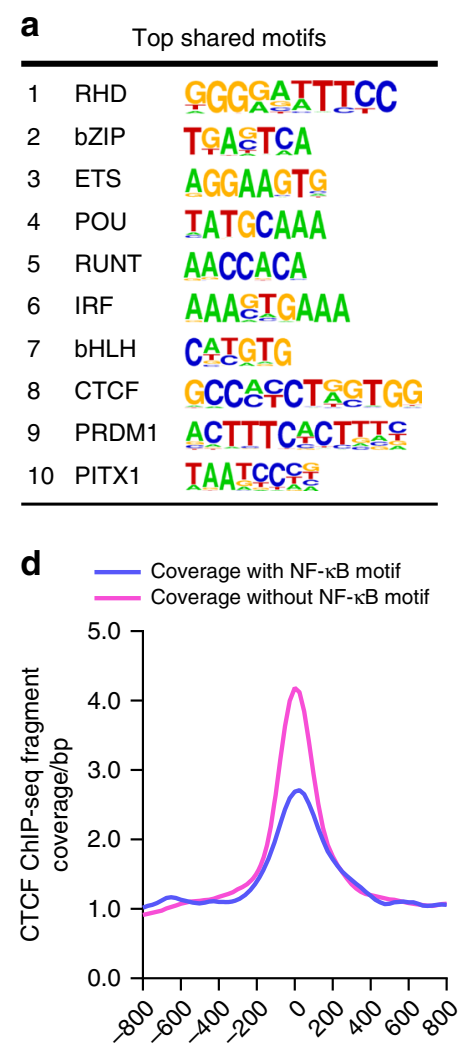

Distance from $\mathrm{p} 65$ peak center
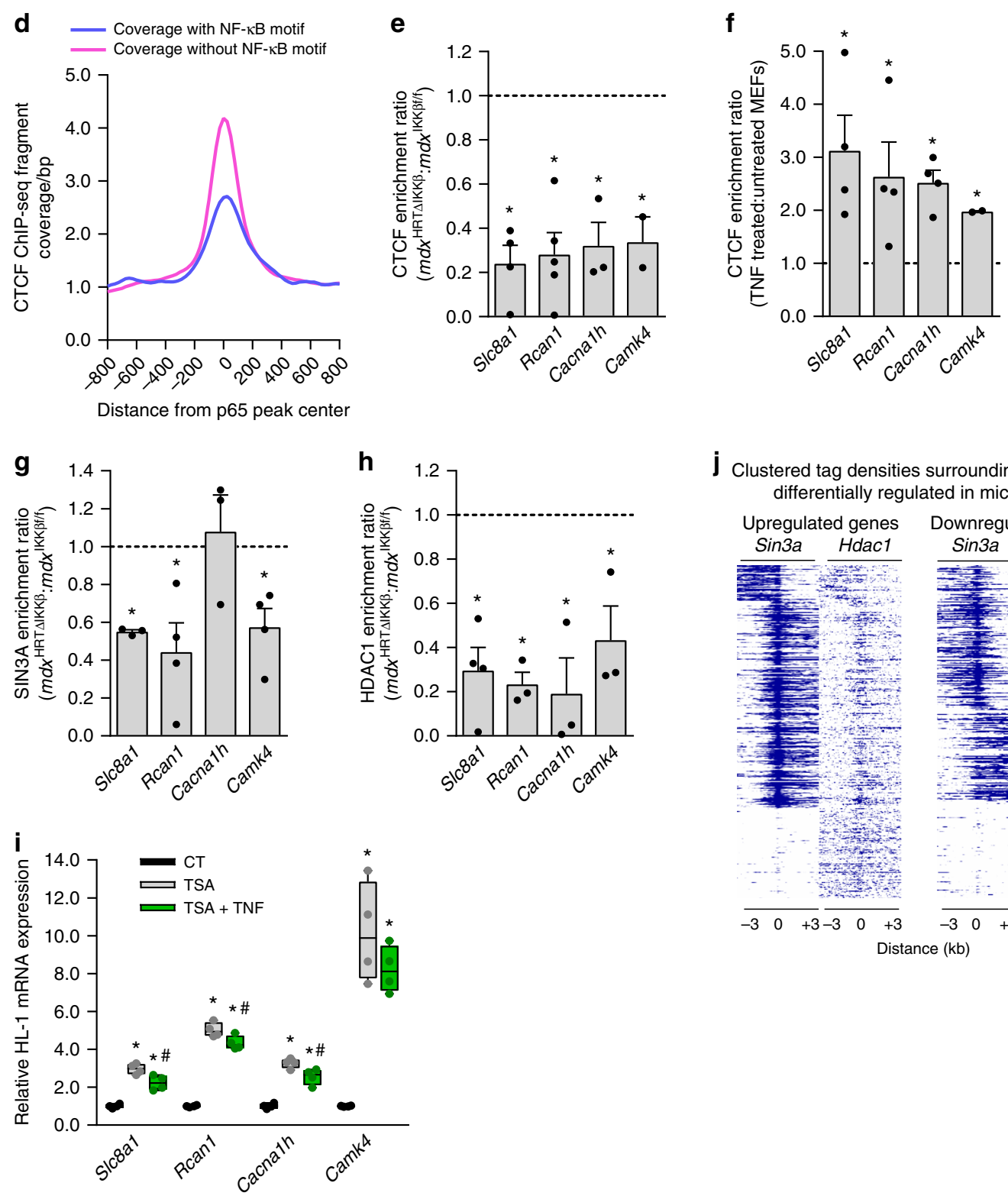

j Clustered tag densities surrounding p65 peaks differentially regulated in microarray
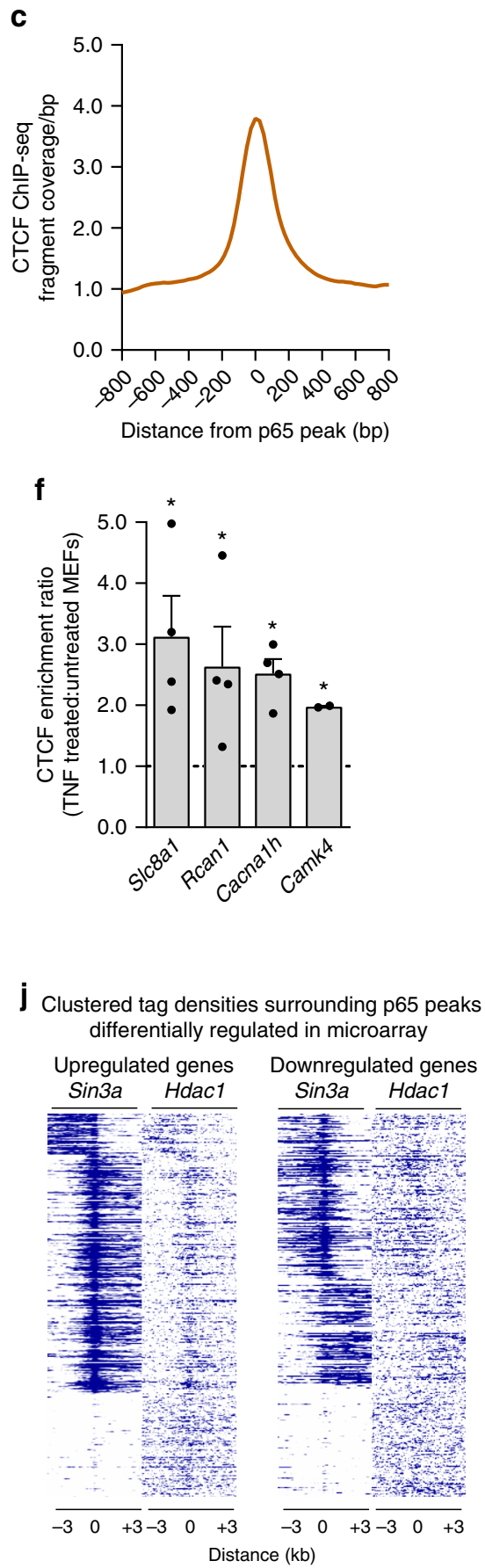

b

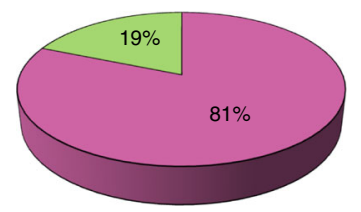

Upregulated genes
with CTCF motifs

Downregulated genes with CTCF motifs

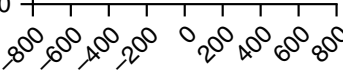

conformation. Thus, in DMD, NF- $\mathrm{BB}$ inhibition alters the enhancers of calcium homeostatic genes, which normalizes cardiac function.

$\mathrm{NF}-\kappa \mathrm{B}$ has previously been shown to interact directly with HDAC1 where it can deacetylate p65, functionally reducing its ability to activate gene expression ${ }^{41}$. Our data suggest that NF- $\kappa B$ also interacts with HDAC1 to assist in the deacetylation of 
Fig. 5 CTCF, SIN3A, and HDAC1 mediate a less permissive chromatin conformation on calcium genes upon NF-kB activation. a Motif analysis performed on genes identified as having both p65 ChIP-seq peaks and H3K27ac mdx HRT $\triangle \mathrm{IKK} \beta$ ChIP-seq regions. b Pie graph representing the percentage of genes with CTCF motifs up- and downregulated in the microarray (relative to $m d x$ hearts with intact NF- $\mathrm{KB}$ ). c ChIP-seq data derived from genome-wide fragment density analysis showing potential overlap of CTCF peaks with p65 peaks. $\mathbf{d}$ The same analysis as in $\mathbf{c}$ except p65 peaks were split between two groups either containing or lacking an NF-kB consensus motif. e-f ChIP performed with a CTCF antibody and qPCR analysis was used to detect enrichment on denoted genes. DNA extracted from e $m d x^{I K K \beta F / f}$ and $m d x{ }^{H R T \Delta I K K} \beta$ hearts $(n=4$ SIc8a1; 5 Rcan $1 ; 3$ cacnalh; 2 Camk4) and (f) control and TNF treated MEFs ( $n=4$ except $n=2$ Camk4), $\mathbf{g}-\mathbf{h}$ The same analyses were performed as in e, f. DNA extracted from $m d x{ }^{I K K} \beta f / f$ and $m d x$ HRT $\Delta I K K \beta$ hearts and ChIP performed with a (g) SIN3A antibody ( $n=3$ S/c8a1 and Cacna1h $(p=0.7) ; n=4$ Rcan1 and Camk4) (h) HDAC1 antibody $(n=3$ except $n=4$ S/c8a1). e-h Enrichment on different genes were plotted as a ratio. Dotted line represents level of enrichment equal to $\mathbf{e}, \mathbf{g}-\mathbf{h} m d x^{I K K \beta f} / \mathrm{f}$ hearts and (f) control MEFs. Bars represent e, $\mathbf{g}-\mathbf{h}$ depletion in $m d x^{H R T \Delta I K K \beta}$ hearts and $\mathbf{f}$ enrichment in TNF treated MEFs. $\mathbf{i}$ Gene expression analyzed by qPCR on total RNA isolated from HL-1 cardiomyocytes $(n=4)$. $\mathbf{j}$ Heatmaps showing ChIP-seq fragment densities of SIN3A and HDAC1 surrounding p65 peaks, showing potential overlap. Left panel includes genes upregulated and right panel includes genes downregulated in the microarray. e-h Data expressed as means \pm SEM with bars and plungers and individual data points with dots. (i) Data expressed using box and whiskers plots. The central line in the boxes is the median value; the lower and upper boundaries of the boxes represent the lower and upper quartiles, respectively; the lower and upper whiskers represent the minimum and maximum values, respectively. Individual data points are plotted with dots. $\mathbf{e}-\mathbf{h}{ }^{\star} p<0.05 \mathrm{mdx} x^{\mathrm{IKK} \beta \mathrm{f} / \mathrm{f}}$ or untreated by 2 -tailed Student's $t$ test. $\mathbf{i}^{\star} p<0.05 \mathrm{CT}$ and $\# p<0.05$ TSA by 1-way ANOVA followed by Tukey multiple comparison test

$\mathrm{DMD}^{42}$. Although HDACi have not been tested for their ability to improve heart function per se, they have been shown to reduce cardiac arrhythmias in $m d x$ mice $^{43}$. In addition, a recent study reported that administration of an HDACi to diabetic mice resulted in improved cardiac function ${ }^{44}$, implying that if $\mathrm{HDACi}$ are approved for the treatment of skeletal muscle pathology in DMD boys, they may have the added benefit of improving heart function.

It is noteworthy that all four of the calcium homeostatic target genes we examined were transcriptionally active in wt hearts. This demonstrates that none of these genes are epigenetically silenced in cardiac muscle, as we anticipated, since their expression contributes to cardiac homeostasis. We made an interesting observation when we compared the expression levels of these calcium genes between wt and $m d x^{\mathrm{IKK} \beta \mathrm{t} / \mathrm{f}}$ hearts. Although $\mathrm{NF}-\kappa \mathrm{B}$ is activated in dystrophic hearts, we find that NF- $\kappa B$ is not acting in its canonical role as a direct transcriptional activator, but rather as a modulator of chromatin conformation to deplete H3K27ac. We anticipated that depletion of $\mathrm{H} 3 \mathrm{~K} 27 \mathrm{ac}$ would result in reduced expression of these calcium target genes, but this was not the case. We speculate that this absence of repression could be due to a compensatory response by a dystrophic heart to activate these genes in attempt to maintain calcium homeostasis and normal heart function. For example, transcriptional regulation of Slc8a1 was previously attributed to MAP kinases ${ }^{45}$, which are also activated in $m d x$ hearts ${ }^{40,46}$. Thus, it is possible that while MAP kinase signaling is actively attempting to upregulate Slc8a1 transcription, activation of NF- $\mathrm{kB}$ is conferring a restricted chromatin conformation, thus limiting access to transcription factors downstream of MAP kinase activity that are needed to stimulate higher Slc8a1 expression. Therefore, with NF- $\kappa$ B inhibition, local chromatin regains a more permissive conformation, allowing access to transcription factors so that a compensatory response occurs and cardiac function is maintained at wt levels. It will be interesting in future studies to address whether the ability of NF- $\kappa \mathrm{B}$ to regulate $\mathrm{H} 3 \mathrm{~K} 27 \mathrm{ac}$ and restrict chromatin confirmation occurs under physiological conditions in normal cardiomyocytes, or as shown with $\mathrm{C} 2 \mathrm{C} 12$ and MEFs, is relevant in other non-cardiac tissues.

Although NF- $\kappa \mathrm{B}$ has not been studied in depth in the context of dystrophic cardiomyopathy, its association in various other models of heart disease has been documented. For example, when NEMO was conditionally deleted from non-diseased mouse hearts, this resulted in aged related dilated cardiomyopathy and fibrosis that could be elicited in younger mice using a pressure overload model ${ }^{47}$. These data are in stark contrast to our findings where we observed improved function with no difference in fibrosis. These differences could be attributed to deletion of IKK $\beta$ vs NEMO, or potentially due to the difference in phenotype when $\mathrm{NF}-\kappa \mathrm{B}$ signaling is interrupted in a disease state (dystrophy) rather than in a normal condition. In heart failure models, inhibiting NF- $\kappa B$ has beneficial effects including improved survival and function, and reduced apoptosis and hypertrophic remodeling ${ }^{48-50}$. Additionally, one report showed that cardiomyocyte p65 deletion preserved calcium handling after ischemiareperfusion injury ${ }^{51}$. This improvement corresponded with increased phosphorylation of serine 16 on phospholamban, resulting in increased sarcoplasmic reticulum calcium uptake. We too observed increased phosphorylation on phospholamban, but perceive this post-translational modification as a downstream event rather than a direct result of $p 65$ deletion since NF- $\kappa B$ subunits do not possess phosphatase activity. NF- $\mathrm{kB}$ inhibition also prevented the development of diabetic cardiomyopathy ${ }^{52}$. Mice were reported to maintain normal calcium handling with no aberrant activation of the renin-angiotensin pathway. These findings are supportive of our conclusion that NF- $\kappa B$ signaling is detrimental to the stressed heart, and that inhibiting this pathway provides beneficial outcomes.

Like NF- $\kappa \mathrm{B}$, the functions of CTCF are vast, and sometimes contradictory. They include maintaining higher order chromatin structure, gene insulation, maintaining borders between euchromatin and heterochromatin, $\mathrm{X}$-inactivation, gene repression, and gene activation ${ }^{39}$. We show that when NF- $\mathrm{KB}$ is activated, CTCF occupies its binding sites, conferring a higher order chromatin conformation on calcium genes that favor a repressive structure. CTCF occupancy was not reduced in the absence of p65, indicating that although $\mathrm{CTCF}$ is responsive to NF- $\mathrm{kB}$ activation, its binding does not require the co-binding of p65. Higher order chromatin conformation changes due to CTCF binding has previously been shown to occur in response to inflammatory induced NF- $\mathrm{BB}$ activation, which is similar to what we have shown, but how this occurred was not elucidated ${ }^{53}$. One group reported that CTCF is a direct transcriptional target of NF- $\mathrm{KB}^{54}$. Although this could explain why in our study CTCF binding was reduced in the absence of NF- $\mathrm{KB}$ activation, in our hands CTCF mRNA expression was unchanged in $m d x$ HRT $\Delta \mathrm{IKK} \beta$ hearts or in $p 65^{-1-}$ compared to $p 65^{+/+}$MEFs. It therefore remains to be determined how CTCF is regulated on calcium genes in response to NF- $\kappa \mathrm{B}$ activation.

We performed this study because there is a need to find effective therapeutics whose mechanism of action is understood, and whose functions are capable of targeting both cardiac and skeletal muscle in DMD. Through our previous genetic studies, we identified mechanisms for how NF- $\mathrm{B}$ signaling is detrimental 
to the skeletal muscles of dystrophic mice and then showed that administration of the NBD peptide improves skeletal muscle pathology and function in both dystrophic mice and canines. We now add to these findings by showing a mechanism for how NF$\kappa \mathrm{B}$ signaling is detrimental to dystrophic cardiac function. To our knowledge, NF- $\kappa B$ represents the first signaling pathway capable of promoting pathology in both dystrophic cardiac and skeletal muscle. Understanding its mode of action in both muscle types now provides stronger rationale for targeting this pathway as a therapeutic for DMD.

\section{Methods}

Mice. Animal use and experimentation for this study was approved by The Ohio State University (OSU) Institutional Animal Care and Use Committee and all experiments were performed in accordance with relevant ethical guidelines and regulations. $M d x$ mice were originally purchased from The Jackson Laboratory $\left(\mathrm{C} 57 \mathrm{BL} / 10 \mathrm{ScSn} \mathrm{DMD}^{m d x}\right.$ ) and have been housed and bred in the animal facilities of OSU for 10 years. Myh6 cre and IKK $\beta$ flox mice were previously created ${ }^{55,56}$. Mice were kept on a 14:10 light-dark cycle with constant temperature and humidity and fed a standard diet. Male mice were used for these studies.

Cell culture. MEFs were previously isolated and immortalized in our lab from $p 65^{+/+}, p 65^{-/-}, p 50^{+/+}$, and $p 50^{-/-}$mice ${ }^{57}$. C2C12 mouse myoblast cell line and $\mathrm{C} 2 \mathrm{C} 12$ cells stably expressing a mutant IкBa plasmid (C2C12 SR) were utilized ${ }^{58}$. Cells were originally obtained from ATCC and cultured in high-glucose DMEM containing $10 \%$ fetal bovine serum and antibiotics. C2C12 myoblasts were differentiated in high-glucose DMEM without sodium butyrate supplemented with $2 \%$ horse serum, $100 \mathrm{ng} \mathrm{ml}^{-1}$ insulin, and antibiotics. HL-1 cardiomyocytes were obtained from SIGMA and cultured in Supplemented Claycomb Medium. Cells were treated with $10 \mathrm{ng} \mathrm{ml}^{-1} \mathrm{TNF}$ for $4 \mathrm{~h}$ (ChIP and gene expression with TSA treatment) or $1 \mathrm{ng} \mathrm{ml}^{-1}$ for 2 days (gene expression with no treatment), $50 \mathrm{nM}$ TSA for $24 \mathrm{~h}$ (MEF and C2C12) or $48 \mathrm{~h}$ (HL-1), $1 \mu \mathrm{M} \mathrm{5-Aza} \mathrm{for} 1$ passage. For combination experiments, 5-Aza was added for one passage then MEFs were treated with TSA for $24 \mathrm{~h}$. For TSA + TNF, cells were treated with TSA for the indicated time (see above) and then treated with TNF for the last $4 \mathrm{~h}$ of experiment. Cells lines were not authenticated or tested for mycoplasma.

NBD mouse administration. NBD peptide was administered by intraperitoneal injections ${ }^{18}$. Injections were performed three times per week for 1 month starting at 6 months of age at a dose of $10 \mathrm{mg} \mathrm{kg}^{-1}$.

EMSA. Electrophoretic mobility shift assay (EMSA) and supershifts were performed using a standard protocol ${ }^{59}$. Hearts were homogenized and nuclear extracts prepared. Extracts were incubated with a radioactive oligonucleotide containing a consensus NF- $\mathrm{kB}$ binding site and fractionated on a $5 \%$ non-denaturing polyacrylamide gel. For supershifts, extracts were incubated with the following antibodies: $4 \mu \mathrm{l}$ p50 (114 Santa Cruz) or IgG or $0.5 \mu \mathrm{l}$ p65 (Rockland) prior to loading on the gel.

Western blotting. Protein was extracted and immunoblotting procedures performed. Primary antibodies: phosphorylated p65 serine 536 (1:1,000, Cell Signaling 3031), p65 (1:10,000; Rockland, non-catalog item), p50 (Santa Cruz, sc-114). Uncropped scans are available in Supplementary Fig. 6.

Tissue preparation and histology. Hearts were either snap frozen for RNA and protein or mounted in OCT and frozen in 2-Methylbutane cooled to the temperature of liquid nitrogen. $10 \mu \mathrm{m}$ sections were prepared on a cryostat. Histological staining was performed for H\&E. Immunohistochemistry was performed using a phosphorylated p65 serine 536 (1:500; Cell Signaling, 3031) primary antibody, HRP goat anti-rabbit IgG (1:250, Vector, BA-1000) secondary antibody and a DAB substrate kit (Vector, SK-4100) for detection.

Multicellular cardiac contractile function. Cardiac muscles were isolated and baseline measures, frequency-dependent activation, and $\beta$-adrenergic stimulation were accessed ex vivo. Under deep anesthesia, hearts were rapidly removed, and flushed with a Krebs-Henseleit solution. The right ventricle was opened, and small papillary muscles were dissected under a stereo microscope. Muscles were mounted in an experimental chamber and superfused with Krebs-Henseleit solution, containing $1.5 \mathrm{mM} \mathrm{Ca}^{2+}$, at $37^{\circ} \mathrm{C}$. Muscles were electrically stimulated to twitch contract, and force of contraction was recorded. For baseline measurements, after the muscle had equilibrated in the set-up, muscle length was increased until a further increase in length no longer resulted in an increase in active twitch developed peak force. This length was then considered optimal length. Frequencydependent stimulation (between 4 and $14 \mathrm{~Hz}$ ), and $\beta$-adrenergic stimulation $(1 \mathrm{nM}$ $-1000 \mathrm{nM}$ Isoproterenol) responses were then determined. Additionally, as a model-independent parameter of force decay kinetics, time from peak force to $90 \%$ relaxation $\left(\mathrm{RT}_{90}\right)$, was determined.

Echocardiography. Echocardiography was performed using a VEVO 2100 Visua Sonics (VisualSonics, Toronto) system. Mice were lightly anesthetized (1.5\% isoflurane) and ejection fraction, fractional shortening, and ventricular chamber dimensions were measured in $\mathrm{M}$ mode using the parasternal short axis view.

Left ventricular pressure-volume relationship analysis. Cardiac hemodynamic measurements were assessed via a closed chest approach using a 1.4 French Millar Pressure catheter (AD Instruments) advanced into the left ventricle through the right carotid artery. Mice were anaesthetized by ketamine $\left(55 \mathrm{mg} \mathrm{kg}^{-1}\right)$ plus xylazine $\left(15 \mathrm{mg} \mathrm{kg}^{-1}\right)$. After $5-10 \mathrm{~min}$ of stabilization, values at baseline and stimulation at varying frequencies $(4-10 \mathrm{~Hz})$ were recorded. Pressure volume loops at $7 \mathrm{~Hz}$ were also obtained at varying preloads via inferior vena cava occlusions to get EDPVR, ESPVR, and PRSW. To measure the beta-adrenergic response, $5 \mathrm{mg} \mathrm{kg}^{-1}$ dobutamine was injected intraperitoneal. All the measurement and analysis were performed on LabChart7 (AdInstruments).

Gene expression analysis. Total RNA was isolated using a standard Trizol extraction protocol. $1 \mu \mathrm{g}$ of RNA and M-MLV reverse transcriptase was used for cDNA synthesis. Quantitative Real-time PCR was performed using SYBR Green on either an Applied Biosystems StepOnePlus or BioRad CFX96 Touch system. All data were normalized to gapdh and the $\Delta \Delta \mathrm{ct}$ method was applied for analysis. Primer sequences are included in Supplementary Table 2.

Microarray. Total RNA was isolated using a standard Trizol extraction protocol and purified with a cleanup kit (Qiagen). A GeneChip Mouse Genome 4302.0 Affymetrix array was used. Gene summary expression estimates were retrieved using Robust multi-array average (RMA) method from probe level data after back ground correction and quantile normalization with Partek software (http://www.rproject.org/). RMA and gene expression data were also independently obtained using Expression Console software from Affymetrix. Gene Set Enrichment Analysis $^{60,61}$ was used for further analysis.

Cardiomyocyte isolation. Cardiomyocytes were isolated by Langendorff perfusion. Hearts were cannulated and perfused with $\mathrm{Ca}^{2+}$ free tyrode solution (Normal tyrode solution in mM: $140 \mathrm{NaCl}, 4 \mathrm{KCl}, 1 \mathrm{MgCl}_{2}, 10$ glucose, and 5 HEPES, $\mathrm{pH}$ 7.4 adjusted with $\mathrm{NaOH}$ or $\mathrm{HCl}$ ) for $5 \mathrm{~min}$. Subsequently, hearts were perfused with a tyrode solution containing Liberase Blendzyme II $\left(0.077 \mathrm{mg} \mathrm{ml}^{-1}\right)$ (Roche Applied Science, Indianapolis, IN). After 4-6 min, hearts were removed from the Langendorff apparatus, the ventricles minced, and myocytes dissociated via trituration. Myocytes were then filtered and centrifuged before being resuspended in a tyrode solution containing $200 \mu \mathrm{M} \mathrm{Ca}^{2+}$.

Myocyte calcium transient measurements. Myocytes were loaded with Flou-4 $\mathrm{Am}(10 \mu \mathrm{M}$, Molecular Probes, Eugene, OR) and incubated for $30 \mathrm{~min}$. Myocytes were then washed and allotted an additional $30 \mathrm{~min}$ for de-esterification. A Cairn Research Limited (Faversham, UK) epifluorescence system was used for intracellular $\mathrm{Ca}^{2+}$ measurements (Fluo-4 epifluorescence with excitation: $480 \pm 20 \mathrm{~nm}$ and emission: $535 \pm 25 \mathrm{~nm}$ ). The change in fluorescent intensity is expressed as $\Delta F / F_{0}$, where $F$ is the fluorescence intensity and $F_{0}$ is the fluorescence intensity at rest.

ChIP. Cells were fixed with $1 \%$ formaldehyde for $8 \mathrm{~min}$ at $37^{\circ} \mathrm{C}$. Formaldehyde was quenched with $1 / 20$ volume of glycine $(2.5 \mathrm{M})$, cells washed with PBS, and scraped in nuclei isolation buffer $(20 \mathrm{mM}$ PIPES (KOH) $\mathrm{pH} 8.0,85 \mathrm{mM} \mathrm{KCl}, 0.5 \% \mathrm{NP}-40$, $1 \mathrm{x}$ protease inhibitors). Nuclear pellets were lysed (10 mM EDTA, $50 \mathrm{mM}$ Tris-HCl $\mathrm{pH} 8.0,1 \%$ SDS, $1 \mathrm{x}$ protease inhibitors) and sonicated with a probe sonicator. Supernatant was precleared with tRNA/Protein G agarose slurry in buffer $(1.2 \mathrm{mM}$ EDTA, $16.7 \mathrm{mM}$ Tris-Hcl pH8.0, $167 \mathrm{mM} \mathrm{NaCl}, 1.1 \%$ Triton-x 100, 0.01\% SDS, $1 \mathrm{x}$ protease inhibitors) for $2 \mathrm{~h}$ then incubated overnight using the following antibodies from Millipore: $3 \mu \mathrm{g}$ H3K27ac (17-683 and 07-360), HDAC1 (17-10199), and IgG (Rabbit, 12-370; Mouse, 12-371), Active Motif: $5 \mu \mathrm{g} \mathrm{H} 3 \mathrm{~K} 9 \mathrm{me} 3$ (61013) and H3K27me3 (39155), Novus: $6 \mu \mathrm{g}$ SIN3A (600-1263), Santa Cruz: $3 \mu \mathrm{g}$ CTCF (5916). For tissue ChIP, sodium heparin was administered to mice prior to excising heart. Hearts were washed in PBS, minced, then simultaneously fixed and homogenized ( $1 \%$ formaldehyde in nuclei isolation buffer) for a total time of $15-20 \mathrm{~min}$ at $4{ }^{\circ} \mathrm{C}$. Nuclei were washed with PBS and then lysed and sonicated as described in cells. Supernatants were precleared for $4 \mathrm{~h}$ and ChIP proceeded as described in cells with the addition of a centrifugation step following overnight antibody incubation Quantitative Real-time PCR was performed using TaqMan (Roche) on a BioRad CFX96 Touch system. Primer sequences are included in Supplementary Table 3.

ChIP-sequencing. ChIP was performed with a $15 \mu \mathrm{g}$ H3K27ac antibody (17-683, Millipore). Purified DNA (10 ng) was end-repaired, and A-nucleotide overhangs were added by incubation with the Taq Klenow fragment lacking exonuclease activity. After the attachment of anchor sequences, fragments were PCR-amplified 
using Illumina-supplied primers. The purified DNA library products were evaluated using Bioanalyzer (Agilent) and SYBR qPCR and diluted to $10 \mathrm{nM}$ for sequencing on HiSeq 2000 sequencer (pair-end with 50bp). A data analysis pipeline SCS v2.5 (Illumina) was employed to perform the initial bioinformatics analysis including base calling and converting the results into raw reads in FASTQ format.

ChIP-sequencing analysis. Bowtie2 was used to map uniquely aligned sequence reads to the mouse reference genome $(\mathrm{mm} 9)^{62}$. HOMER (Hypergeometric Optimization of Motif EnRichment) software suite was used to create tag directories, for peak calling and annotation, for motif analysis, to create histograms, determine differentially enriched peaks, and generate a data matrix for heatmaps ${ }^{63}$. ChIPseeker software was used to visualize genomic regions of H3K27ac binding and binding relative to TSS ${ }^{64}$. Metascape was used to identify pathway enrichment in differential peaks [http://metascape.org] ${ }^{65}$. Cytoscape was used to visualize the clustered pathways ${ }^{66}$. Cluster $3.0^{67}$ was used to cluster the data matrix files and Java TreeView ${ }^{68}$ was used to visualize these data in heatmaps.

Publicly available data. The following publicly available ChIP-seq data sets were used. 8-week old hearts were from the ENCODE Consortium produced by the Ren $\mathrm{lab}^{69}$. H3K27ac (GSM1000093), H3K4mel (GSM769025), H3K36me3

(GSM1000130), CTCF (GSM918756). p65 was from LPS treated bone marrow derived macrophages (GSM611116; GSM611117). Our previous microarray was in Ras transformed MEFs (GSE59545).

Statistics. All data were expressed as mean \pm SEM. Results were analyzed by an unpaired 2-tailed Student's $t$ test, 1-way ANOVA, or repeated measures 2-way ANOVA as appropriate. Data met the requirements for performing the appropriate test. A P value of less than 0.05 was considered statistically significant. Statistical analysis was performed using GraphPad Prism 6.0 software (GraphPad Software). Samples sizes were estimated based on previous studies. All samples represent biological replicates. Representative western blots and EMSAs were repeated twice. For mouse studies, data were excluded if values could not be obtained from the sample or equipment malfunction prevented obtaining data. Randomization was not used. For physiology experiments, the investigator was blinded to the group being analyzed.

Data availability. The data that support the finding of this study are available from the corresponding author on request. Microarray and ChIP-seq data have been deposited into the GEO database under accession code GSE114026. SubSeries: GSE114023 and GSE114025.

Received: 30 December 2016 Accepted: 25 July 2018

Published online: 24 August 2018

\section{References}

1. Hoffman, E. P., Brown, R. H. Jr. \& Kunkel, L. M. Dystrophin: the protein product of the Duchenne muscular dystrophy locus. Cell 51, 919-928 (1987).

2. Towbin, J. A. et al. X-linked dilated cardiomyopathy. Molecular genetic evidence of linkage to the Duchenne muscular dystrophy (dystrophin) gene at the Xp21 locus. Circulation 87, 1854-1865 (1993).

3. Milasin, J. et al. A point mutation in the $5^{\prime}$ splice site of the dystrophin gene first intron responsible for X-linked dilated cardiomyopathy. Hum. Mol. Genet. 5, 73-79 (1996).

4. Vatta, M. et al. Molecular remodelling of dystrophin in patients with end-stage cardiomyopathies and reversal in patients on assistance-device therapy. Lancet 359, 936-941 (2002).

5. Rodriguez, M., Cai, W. J., Kostin, S., Lucchesi, B. R. \& Schaper, J. Ischemia depletes dystrophin and inhibits protein synthesis in the canine heart: mechanisms of myocardial ischemic injury. J. Mol. Cell. Cardiol. 38, 723-733 (2005).

6. Andreoletti, L. et al. Active Coxsackieviral B infection is associated with disruption of dystrophin in endomyocardial tissue of patients who died suddenly of acute myocardial infarction. J. Am. Coll. Cardiol. 50, 2207-2214 (2007).

7. Armstrong, S. C., Latham, C. A., Shivell, C. L. \& Ganote, C. E. Ischemic loss of sarcolemmal dystrophin and spectrin: correlation with myocardial injury. J. Mol. Cell. Cardiol. 33, 1165-1179 (2001).

8. Badorff, C. et al. Enteroviral protease 2A cleaves dystrophin: evidence of cytoskeletal disruption in an acquired cardiomyopathy. Nat. Med. 5, 320-326 (1999).

9. McNally, E. M. New approaches in the therapy of cardiomyopathy in muscular dystrophy. Annu. Rev. Med. 58, 75-88 (2007).
10. Burr, A. R. \& Molkentin, J. D. Genetic evidence in the mouse solidifies the calcium hypothesis of myofiber death in muscular dystrophy. Cell Death Differ. 22, 1402-1412 (2015).

11. Finsterer, J. \& Cripe, L. Treatment of dystrophin cardiomyopathies. Nat. Rev. Cardiol. 11, 168-179 (2014).

12. Hayden, M. S. \& Ghosh, S. NF-kappaB, the first quarter-century: remarkable progress and outstanding questions. Genes Dev. 26, 203-234 (2012).

13. Gu, J. M. et al. An NF-kappaB-EphrinA5-dependent communication between NG2(+) interstitial cells and myoblasts promotes muscle growth in neonates. Dev. Cell. 36, 215-224 (2016).

14. He, W. A. et al. NF-kappaB-mediated Pax7 dysregulation in the muscle microenvironment promotes cancer cachexia. J. Clin. Invest. 123, 4821-4835 (2013).

15. Peterson, J. M., Bakkar, N. \& Guttridge, D. C. NF-kappaB signaling in skeletal muscle health and disease. Curr. Top. Dev. Biol. 96, 85-119 (2011).

16. Shintaku, J. et al. MyoD regulates skeletal muscle oxidative metabolism cooperatively with alternative NF-kappaB. Cell Rep. 17, 514-526 (2016).

17. Peterson, J. M. et al. Peptide-based inhibition of NF-kappaB rescues diaphragm muscle contractile dysfunction in a murine model of Duchenne muscular dystrophy. Mol. Med. 17, 508-515 (2011).

18. Acharyya, S. et al. Interplay of IKK/NF-kappaB signaling in macrophages and myofibers promotes muscle degeneration in Duchenne muscular dystrophy. $J$. Clin. Invest. 117, 889-901 (2007).

19. Lu, A. et al. NF-kappaB negatively impacts the myogenic potential of musclederived stem cells. Mol. Ther. 20, 661-668 (2012).

20. Tang, Y. et al. Inhibition of the IKK/NF-kappaB pathway by AAV gene transfer improves muscle regeneration in older mdx mice. Gene Ther. 17, 1476-1483 (2010)

21. Yang, Q. et al. AAV-based shRNA silencing of NF-kappaB ameliorates muscle pathologies in mdx mice. Gene Ther. 19, 1196-1204 (2012).

22. Strickland, I. \& Ghosh, S. Use of cell permeable NBD peptides for suppression of inflammation. Ann. Rheum. Dis. 65, iii75-iii82 (2006).

23. Kornegay, J. N. et al. NBD delivery improves the disease phenotype of the golden retriever model of Duchenne muscular dystrophy. Skelet. Muscle 4, 18 (2014).

24. Delfin, D. A. et al. Improvement of cardiac contractile function by peptidebased inhibition of NF-kappaB in the utrophin/dystrophin-deficient murine model of muscular dystrophy. J. Transl. Med. 9, 68 (2011).

25. Danialou, G. et al. Dystrophin-deficient cardiomyocytes are abnormally vulnerable to mechanical stress-induced contractile failure and injury. Faseb. J. 15, 1655-1657 (2001).

26. Janssen, P. M., Hiranandani, N., Mays, T. A. \& Rafael-Fortney, J. A. Utrophin deficiency worsens cardiac contractile dysfunction present in dystrophindeficient mdx mice. Am. J. Physiol. Heart Circ. Physiol. 289, H2373-H2378 (2005).

27. Li, W., Liu, W., Zhong, J. \& Yu, X. Early manifestation of alteration in cardiac function in dystrophin deficient $\mathrm{mdx}$ mouse using 3D CMR tagging. $J$. Cardiovasc. Magn. Reson. 11, 40 (2009).

28. Quinlan, J. G. et al. Evolution of the mdx mouse cardiomyopathy: physiological and morphological findings. Neuromuscul. Disord. 14, 491-496 (2004).

29. Spurney, C. F. et al. Dystrophin-deficient cardiomyopathy in mouse: expression of Nox4 and Lox are associated with fibrosis and altered functional parameters in the heart. Neuromuscul. Disord. 18, 371-381 (2008).

30. Fayssoil, A. et al. Cardiac characterization of $\mathrm{mdx}$ mice using high-resolution doppler echocardiography. J. Ultrasound Med. 32, 757-761 (2013).

31. Bostick, B., Yue, Y. \& Duan, D. Gender influences cardiac function in the $\mathrm{mdx}$ model of Duchenne cardiomyopathy. Muscle Nerve 42, 600-603 (2010).

32. Bostick, B., Shin, J. H., Yue, Y. \& Duan, D. AAV-microdystrophin therapy improves cardiac performance in aged female mdx mice. Mol. Ther. 19, 1826-1832 (2011).

33. Ho, D., Yan, L., Iwatsubo, K., Vatner, D. E. \& Vatner, S. F. Modulation of beta-adrenergic receptor signaling in heart failure and longevity: targeting adenylyl cyclase type 5. Heart Fail. Rev. 15, 495-512 (2010).

34. Wang, D. J., Ratnam, N. M., Byrd, J. C. \& Guttridge, D. C. NF-kappaB functions in tumor initiation by suppressing the surveillance of both innate and adaptive immune cells. Cell Rep. 9, 90-103 (2014).

35. Zhou, A., Scoggin, S., Gaynor, R. B. \& Williams, N. S. Identification of NFkappa B-regulated genes induced by TNFalpha utilizing expression profiling and RNA interference. Oncogene 22, 2054-2064 (2003).

36. Lee, S. L., Yu, A. S. \& Lytton, J. Tissue-specific expression of $\mathrm{Na}(+)-\mathrm{Ca} 2$ +exchanger isoforms. J. Biol. Chem. 269, 14849-14852 (1994).

37. Wang, H. et al. NF-kappaB-YY1-miR-29 regulatory circuitry in skeletal myogenesis and rhabdomyosarcoma. Cancer Cell. 14, 369-381 (2008).

38. Wang, H. et al. NF-kappaB regulation of YY1 inhibits skeletal myogenesis through transcriptional silencing of myofibrillar genes. Mol. Cell. Biol. 27, 4374-4387 (2007) 
39. Holwerda, S. J. \& de Laat, W. CTCF: the protein, the binding partners, the binding sites and their chromatin loops. Philos. Trans. R. Soc. Lond. B. Biol. Sci. 368, 20120369 (2013).

40. Nakamura, A., Harrod, G. V. \& Davies, K. E. Activation of calcineurin and stress activated protein kinase/p38-mitogen activated protein kinase in hearts of utrophin-dystrophin knockout mice. Neuromuscul. Disord. 11, 251-259 (2001).

41. Ashburner, B. P., Westerheide, S. D. \& Baldwin, A. S. Jr. The p65 (RelA) subunit of NF-kappaB interacts with the histone deacetylase (HDAC) corepressors $\mathrm{HDAC} 1$ and $\mathrm{HDAC} 2$ to negatively regulate gene expression. Mol. Cell. Biol. 21, 7065-7077 (2001).

42. Bettica, P. et al. Histological effects of givinostat in boys with Duchenne muscular dystrophy. Neuromuscul. Disord. 26, 643-649 (2016).

43. Colussi, C. et al. The histone deacetylase inhibitor suberoylanilide hydroxamic acid reduces cardiac arrhythmias in dystrophic mice. Cardiovasc. Res. 87, 73-82 (2010).

44. Chen, Y. et al. Histone deacetylase (HDAC) inhibition improves myocardial function and prevents cardiac remodeling in diabetic mice. Cardiovasc. Diabetol. 14, 99 (2015).

45. Sirabella, R. et al. ERK1/2, p38, and JNK regulate the expression and the activity of the three isoforms of the $\mathrm{Na}+/ \mathrm{Ca} 2+$ exchanger, NCX1, NCX2, and NCX3, in neuronal PC12 cells. J. Neurochem. 122, 911-922 (2012).

46. Nakamura, A., Yoshida, K., Takeda, S., Dohi, N. \& Ikeda, S. Progression of dystrophic features and activation of mitogen-activated protein kinases and calcineurin by physical exercise, in hearts of mdx mice. FEBS Lett. 520, 18-24 (2002).

47. Kratsios, P. et al. Antioxidant amelioration of dilated cardiomyopathy caused by conditional deletion of NEMO/IKK\{gamma\} in cardiomyocytes. Circ. Res. (2009).

48. Hamid, T. et al. Cardiomyocyte NF-kappaB p65 promotes adverse remodelling, apoptosis, and endoplasmic reticulum stress in heart failure. Cardiovasc. Res. 89, 129-138 (2011).

49. Young, D., Popovic, Z. B., Jones, W. K. \& Gupta, S. Blockade of NF-kappaB using IkappaB alpha dominant-negative mice ameliorates cardiac hypertrophy in myotrophin-overexpressed transgenic mice. J. Mol. Biol. 381, 559-568 (2008).

50. Liu, Q., Chen, Y., Auger-Messier, M. \& Molkentin, J. D. Interaction between NFkappaB and NFAT coordinates cardiac hypertrophy and pathological remodeling. Circ. Res. 110, 1077-1086 (2012).

51. Zhang, X. Q. et al. Cardiomyocyte-specific p65 NF-kappaB deletion protects the injured heart by preservation of calcium handling. Am. J. Physiol. Heart Circ. Physiol. 305, H1089-H1097 (2013).

52. Thomas, C. M. et al. Cardiac-specific suppression of NF-kappaB signaling prevents diabetic cardiomyopathy via inhibition of the renin-angiotensin system. Am. J. Physiol. Heart Circ. Physiol. 307, H1036-H1045 (2014).

53. Watanabe, T. et al. Higher-order chromatin regulation and differential gene expression in the human tumor necrosis factor/lymphotoxin locus in hepatocellular carcinoma cells. Mol. Cell. Biol. 32, 1529-1541 (2012).

54. Lu, L., Wang, L., Li, T. \& Wang, J. NF-kappaB subtypes regulate CCCTC binding factor affecting corneal epithelial cell fate. J. Biol. Chem. $\mathbf{2 8 5}$ 9373-9382 (2010).

55. Abel, E. D. et al. Cardiac hypertrophy with preserved contractile function after selective deletion of GLUT4 from the heart. J. Clin. Invest. 104, 1703-1714 (1999).

56. Li, Z. W., Omori, S. A., Labuda, T., Karin, M. \& Rickert, R. C. IKK beta is required for peripheral B cell survival and proliferation. J. Immunol. 170, 4630-4637 (2003).

57. Wang, J. et al. RelA/p65 functions to maintain cellular senescence by regulating genomic stability and DNA repair. EMBO Rep. 10, 1272-1278 (2009).

58. Guttridge, D. C., Albanese, C., Reuther, J. Y., Pestell, R. G. \& Baldwin, A. S. Jr. NF-kappaB controls cell growth and differentiation through transcriptional regulation of cyclin D1. Mol. Cell. Biol. 19, 5785-5799 (1999).

59. Dahlman, J. M. \& Guttridge, D. C. Detection of NF-kappaB activity in skeletal muscle cells by electrophoretic mobility shift analysis. Methods Mol. Biol. 798, 505-516 (2012).

60. Mootha, V. K. et al. PGC-1alpha-responsive genes involved in oxidative phosphorylation are coordinately downregulated in human diabetes. Nat. Genet. 34, 267-273 (2003).

61. Subramanian, A. et al. Gene set enrichment analysis: a knowledge-based approach for interpreting genome-wide expression profiles. Proc. Natl Acad. Sci. USA 102, 15545-15550 (2005).

62. Langmead, B., Trapnell, C., Pop, M. \& Salzberg, S. L. Ultrafast and memoryefficient alignment of short DNA sequences to the human genome. Genome Biol. 10, R25 (2009).
63. Heinz, S. et al. Simple combinations of lineage-determining transcription factors prime cis-regulatory elements required for macrophage and B cell identities. Mol. Cell 38, 576-589 (2010).

64. Yu, G., Wang, L. G. \& He, Q. Y. ChIPseeker: an R/Bioconductor package for ChIP peak annotation, comparison and visualization. Bioinformatics 31, 2382-2383 (2015).

65. Tripathi, S. et al. Meta- and orthogonal integration of influenza "OMICs" data defines a role for UBR4 in virus budding. Cell. Host. Microbe 18, 723-735 (2015).

66. Shannon, P. et al. Cytoscape: a software environment for integrated models of biomolecular interaction networks. Genome Res. 13, 2498-2504 (2003).

67. de Hoon, M. J., Imoto, S., Nolan, J. \& Miyano, S. Open source clustering software. Bioinformatics 20, 1453-1454 (2004).

68. Saldanha, A. J. Java Treeview-extensible visualization of microarray data. Bioinformatics 20, 3246-3248 (2004).

69. Consortium, E. P. An integrated encyclopedia of DNA elements in the human genome. Nature 489, 57-74 (2012).

\section{Acknowledgements}

We are grateful to J.A. Rafael-Fortney, M.R. Parthun, and past and present members of the Guttridge lab for their helpful discussions throughout this study. We thank B.P. Ashburner for kindly sharing reagents. We very much appreciate J. Brice and D. Bryant in the Ohio State University Solid Tumor Biology Program histology core for their patience and assistance preparing whole heart sections, and S. Cole and B. Kemmenoe in the OSU Campus Microscopy and Imaging Facility for their assistance in capturing images. Support for this work was provided by grants from the National Institutes of Health: U01 NS058451 (D.C.G. and P.M.L.J.), F32 HL099145 (J.M. Peterson), R01 AR044719 (S.M.S.), as well as the Muscular Dystrophy Association (J.M. Peterson), and Parent Project Muscular Dystrophy (D.C.G.).

\section{Author contributions}

J.M. Peterson designed the study, collected, and analyzed the data, and wrote the manuscript. D.J.W. provided experimental expertize and guidance throughout the study. V.S., S.R.R., B.D.C., and S.C.L. performed physiology measurements. N.B., J.S., and J.-M. G. provided experimental expertize for various aspects of the study. L.L. performed ChIP sequencing. N.M.R., C.E.G., and J.M. Petrosino assisted with data collection. P.L. performed co-immunoprecipitations, S.L. assisted with microarray analysis. H.W. provided expertize with and performed ChIP sequencing. P.M.L.J., J.P.D., and M.T.Z. designed and assisted with analysis and interpretation of physiology data. S.M.S. assisted in bioinformatics pipeline development and bioinformatics analysis and provided expertize in ChIP assays. D.C.G. designed and mentored the study and assisted in preparation of the manuscript. All authors approved the final manuscript version.

\section{Additional information}

Supplementary Information accompanies this paper at https://doi.org/10.1038/s41467018-05910-1.

Competing interests: The authors declare no competing interests.

Reprints and permission information is available online at http://npg.nature.com/ reprintsandpermissions/

Publisher's note: Springer Nature remains neutral with regard to jurisdictional claims in published maps and institutional affiliations.

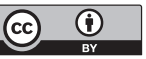

Open Access This article is licensed under a Creative Commons Attribution 4.0 International License, which permits use, sharing, adaptation, distribution and reproduction in any medium or format, as long as you give appropriate credit to the original author(s) and the source, provide a link to the Creative Commons license, and indicate if changes were made. The images or other third party material in this article are included in the article's Creative Commons license, unless indicated otherwise in a credit line to the material. If material is not included in the article's Creative Commons license and your intended use is not permitted by statutory regulation or exceeds the permitted use, you will need to obtain permission directly from the copyright holder. To view a copy of this license, visit http://creativecommons.org/ licenses/by/4.0/.

(c) The Author(s) 2018 